\title{
Retrieval of Marine Surface Slick Dielectric Properties from Radarsat-2 data via a Polarimetric Two-Scale Model
}

\author{
Cornelius Quigley, Camilla Brekke, Member, IEEE, Torbjørn Eltoft, Member, IEEE
}

\begin{abstract}
We propose the use of a polarimetric two-scale surface scattering model to retrieve the dielectric parameters of oil slick from polarimetric synthetic aperture radar. The ocean surface is modeled as an ensemble of randomly orientated, slightly roughened, tilted facets for which the small perturbation model is assumed to be valid under the condition of no tilt. The orientation of the random facets causes a variation in the in-plane and out-of-plane tilt angles. As the original model utilizes both the co-polarization and cross-polarization channels to determine both the dielectric and roughness characteristics simultaneously from a series of look-up tables, the model is adapted from its original form in order to estimate the roughness characteristics of the scattering surface first, before the dielectric properties are inferred. The performance of the altered scattering model is then evaluated by applying it to multiple sets of quad-polarimetric data containing verified oil slicks, acquired from oil-on-water clean-up exercises in the North Sea. Histograms of retrieved values for the modulus of the dielectric constant indicate that the model is able to invert for values similar to the actual value of 2.3 , the dielectric constant of pure crude oil at the lower limit, with successively higher values being found up to values of approximately 20 at the edges of the slicks. An error evaluation is also presented and demonstrates that sources of error are related to the alteration of the model to suit co-polarimetric data and the variance of the speckle which is related to the size of the averaging window. While the results are interesting, the approach is limited to the use of only the ratio of the co-polarimetric channels, from which two unknowns are estimated.
\end{abstract}

Index Terms-dielectric properties, look-alike, oil spill, surface slick characterization, synthetic aperture radar

\section{INTRODUCTION}

$\mathrm{T}$ HE inclusion of mineral oil into the marine environment represents a major ecological concern. According to [1] each year at between 2000 to 3000 instances of illegal dumping of mineral oil take place in European waters. Having reliable and timely information on the location and physical properties

This work was supported by CIRFA, CIRFA partner Total E\&P Norge AS and the Research Council of Norway under Grant 237906.

C. Quigley, T. Eltoft and C. Brekke are with the Department of Physics and Technology, UiT - The Arctic University of Norway, NO-9037 Tromsø, Norway (e-mail: cornelius.p.quigley@uit.no, torbjorn.eltoft@uit.no, camilla.brekke@uit.no).

Manuscript received of such spills is of great importance for the clean-up efforts of first responders. Some considerations that are usually taken into account when major spill events occur, are determination of the extent of a discharge, determination of the effectiveness of spill countermeasures, understanding the physical distribution of oil on the sea surface, in relation to the location of zones of variable thickness and oil concentration within slick, rates of spreading and transport, and the volumetric amount of oil spilled [2].

For these purposes, there is currently a large international effort to develop techniques to assess the thickness of oil slick, and the thickness regimes within, using remote sensing technology $[3,4]$. These inhomogeneities in thickness within slick, are believed to arise from spatial variations in water uptake and spatial variations in rates of spreading within slick, which alter the roughness and dielectric characteristics of the bulk material. The focus of this work is on the determination of the dielectric constant of verified oil slicks which can be used to retrieve the volumetric fraction of oil contained within the oil/water mix.

However, research into the determination of thickness regimes that exist within marine slicks is in its infancy. The most common method used today in order to differentiate between regions of oil slick with variable thickness is based on visual means via the Bonn Agreement Oil Appearance Codes (BAOAC). However, these are limited in that they are based on subjective assessment and are not always able to provide a synoptic estimate of the state of an oil slick [5].

Due to the volume of illegal discharges, reliable techniques that provide some indication of the spatial concentration of mineral oils derived from space-borne sensors, with higher spatial resolutions that offer timely and synoptic-scale views of the Earth's oceans, are needed to insure rapid response times and effective monitoring capabilities. However, given that the vast majority of oil discharges are not of the type seen in ship accidents or oil rig disasters, but are a result of routine ship operations such as tank washing and engine effluent discharges (sludge) [6], the spatial extent of such discharges will not be of the same scale of the spatial resolution of spaceborne microwave radiometers or optical sensors [7]. Synthetic Aperture Radar (SAR) has proven itself to be an indispensable tool for this application.

Recent studies have shown that IR airborne data, which is believed to be sensitive to the thickness regimes within oil slick, shows a strong correlation with SAR data [8], indicating that SAR is capable of discerning the thickness information within slick.

Mineral oils, that are present in the marine environment, are easily detectible by SAR sensors as they manifest themselves 
as dark patches in SAR imagery. These dark patches can occur via two physical mechanisms. The first, is that they dampen the short-scale wind induced surface waves, which reduces the short-scale roughness of the ocean surface, resulting in a reduction of backscatter to the sensor [9]. This reduction in backscatter necessitates the use of sensors that can provide a reasonable signal-to-noise ratio (SNR) for the determination of the dielectric properties of oil slick.

The second mechanism concerns the fate of mineral oil when it is included into the marine environment. When mineral oil is included into the marine environment it becomes subjected to a host of processes collectively referred to as weathering [10]. One such process is emulsification, whereby sea water becomes entrained into the oil, which has the effect of reducing the effective dielectric constant of the ocean surface. These water-in-oil mixtures can result in a reduction of backscatter to the radar if the oil is mixed in high enough concentrations within a thin layer below the ocean surface. The ability of a SAR to detect changes in the apparent dielectric constant, due to the presence of oil, is dependent on the thickness of the layer of oil relative to the wavelength of the incoming radiation. According to [11], this corresponds to a few millimeters for a radar with a wavelength of $24 \mathrm{~cm}$ and occurs as a lower dielectric constant means less energy will be reflected by the surface.

Via the application of theoretical scattering models, it should be possible to invert the returned backscatter to the SAR for the effective dielectric constant of the water-oil mixture. The evaluated dielectric value is fed into a mixing model which is inverted to determine the volumetric content of oil in a pixel, or the inverted dielectric values can be used to provide a heuristic based assessment on where there are greater amounts of oil within slick compared to other areas. Given that an estimation for the amount of oil present is usually the one of the first parameters that is determined after an oil spill, and is based on rules-of-thumb related to the apparent color of oil observed from manned observation platforms [2], current techniques that can offer objective assessments of oil slick are needed to be improved.

This method for directly determining $|\varepsilon|$, the absolute value of the complex permittivity, of marine surface slicks in SAR imagery via the application of scattering models is a highly under developed topic with no known publications on the matter currently existing. One notable exception however is [12] who attempted to estimate the concentration of pollutant within an oil-in-water mixture using a Universal Weighted Curvature Approximation (U-WCA) scattering model in conjunction with L-band SAR data. The authors of this study demonstrate that with the use of a rigorous theoretical scattering model and SAR data with high SNR, it may be possible to infer reasonable estimates for the volumetric content of oil within a pixel. Despite the fact that no in-situ data was reported, the authors state that the estimation was robust to uncertainties related to sea state and are consistent with the expected behavior of an oil slick imaged area.

Other notable studies that attempt to relate the ratio of oil mixed into water to the Normalized Radar Cross Section (NRCS)/polarimetric features include [11,13] who employ a classification scheme called the oil/water mixing index (Mdex), developed by [11], that aims to link the total backscatter received to the sensor to the BAOAC for aerial observers of oil spills. This index, a value ranging from -1 to 1 , shows more heterogenous areas within the slick than the NRCS image and promulgates a common communication mode for optical and SAR observations. Li et. al. [14] also attempted to determine the oil-water mixture ratio by employing the ratio of the diagonal elements of the covariance matrix for simulated Compact Polarimetry (CP) SAR from L-band UAVSAR data taken over the Deepwater Horizon (DWH) incident. While the results of this study were promising, the authors conclude that extensions of this method requires further work, as DWH represented an unprecedent oil spill event and the study was carried out using solely air bourn data.

Currently, one of the most frequently used polarimetric surface scattering models employed within the field of oil spill remote sensing is the extended Bragg (X-Bragg) model which was developed by [15]. The X-Bragg model extends the range of validity of the Small Perturbation Method (SPM), which is widely understood to be a good candidate for describing the scattering from slightly rough surfaces, by taking into account cross-polarization and depolarization effects while also retaining a tractable formulation. Within the X-Bragg formulation, the ocean surface is treated as being composed of slightly roughened tilted facets where the scattering from each facet is still evaluated via the SPM. The facet random tilt causes a variation in both the incidence angle, denoted by $\Delta v$, and a random rotation $\beta$ in the local incidence plane around the line of sight. The term incidence here refers to the angle between the incoming radiation and the normal to an untilted, flat surface and has the same numeric value as the SAR look angle. In [15], the random variation in incidence angle $\Delta v$, is ignored and the incidence plane rotation $\beta$ is assumed to be uniformly distributed within an interval $\left(-\beta_{1}, \beta_{1}\right)$, where $\beta_{1}$ is a parameter that is used to characterize the ocean surface roughness.

In this study, a Polarimetric Two-Scale Model (PTSM) that is described in [16] is used to invert the co-polarimetric ratio for the absolute value of the complex permittivity $|\varepsilon|$. The PTSM improves upon the X-Bragg model by removing the simplifying assumptions of no $\Delta v$ and a uniform $\beta$. By describing the scattering surface as a stochastic process, the conclusion that the facet slopes along the range and azimuth directions are zeromean Gaussian random variables with the same standard deviation, $\mathrm{s}$, is reached. This standard deviation characterizes the gravity waves of the ocean surface. As $\beta$ and $\Delta v$ can be linked to the facet slopes via geometrical arguments [16], the NRCS of the overall surface can then be found by simply averaging the SPM over the random facet slopes. This will be discussed in more detail in Section III.

The model is applied to four data sets, acquired by Radarsat2, during the Norwegian Clean Seas Association for Operating Companies (NOFO) annual oil-on-water clean-up exercise held off the cost of Norway. The values of $|\varepsilon|$ obtained within oil slick ranged between 1 and 20 approximately, and between 20 to 165 for areas of open water. The value of 165 being an arbitrary upper-limit for which the model was allowed to run for. While the oil seems to be slightly underestimated for the lowest values within the slick, they are not significantly different from the actual value of 2.3 approximately. After 
inversion, it was also noted that areas of thin oil sheen and areas of low wind (a very common oil spill look-alike) were observed to be indistinguishable from the surrounding ocean. These results indicate that inversion of polarimetric data of oil slick imagery into $|\varepsilon|$ values can provide fast and reliable imagery indicating slick concentration, that are robust to some lookalike phenomena that tend to be present in SAR imagery.

This paper is organized as follows. Section II introduces the reader to some important aspects of ocean surface slicks. Section III outlines the PTSM. Section IV outlines the inversion procedure that was employed. Section V introduces the data sets that are used as well as the process that outputted slicks were subjected to. The inversion results are presented in section VI. Section VII concludes the paper.

\section{CHARACTERISTICS OF OCEAN SURFACE SLICKS}

\section{A. Types of Marine Surface Slick}

The three main slick types that are represented in the data of section $\mathrm{V}$ are simulators of natural biogenic slicks, slicks of emulsion and slicks of pure crude oil at the time of release.

Biogenic slicks are comprised of surface-active organic compounds that originate from marine plants and animals and contain a hydrophobic part and a hydrophilic part. The term 'surface-active' here refers to compounds that accumulate at the water surface. This ambiphilic chemical structure means that these molecules have a tendency to orientate themselves both towards and away from the water. As a consequence, the molecules are arranged at the ocean/atmosphere interface such that the hydrophobic part is directed into the air and the hydrophilic part is directed into the ocean. The result is a monolayer of molecules on the ocean surface [17].

Crude oils are complex chemical compounds that consist of alkanes, cycloalkanes and aromatic compounds [18]. In its natural unrefined state, crude oils can vary dramatically in characteristics depending on the location in which they are found. When crude oils are inserted into the marine environment they tend to spread out over time. In contrast to monomolecular films, crude oil slicks tend to have thicknesses orders of magnitude larger than monomolecular films [17].

Throughout this paper, slicks of emulsion will refer to mixtures of crude oil and sea water. According to theory, as oil is subjected to the marine environment water will begin to become entrained in the bulk material which generally occurs in the presence of wave breaking when wind speeds are greater than $7 \mathrm{~m} / \mathrm{s}[6]$.

\section{B. Slick Characteristics and Weathering}

The viscosity of a liquid refers to its resistance to flow. The viscosity that an oil will have is dependent on the ambient temperature of its environment $[18,19]$. In general, the viscosity of crude oils will tend to be larger than that of natural oils. This means that crude oils will tend to spread out less rapidly than biogenic slicks and will have less homogenous regions in oil thickness and volumetric water content [20].

The dielectric constant is a property of matter that indicates a mediums ability to allow the propagation of electromagnetic radiation and is an intrinsic property of that material. The complex electric permittivity is expressed as

$$
\varepsilon(\omega)=\varepsilon^{\prime}(\omega)-j \varepsilon^{\prime \prime}(\omega)
$$

The real part, $\varepsilon^{\prime}(\omega)$, describes a mediums ability to store electrical charge while the imaginary part, $\varepsilon^{\prime \prime}(\omega)$, known as the loss factor, describes the electromagnetic loss in a medium. $j$ has the value $\sqrt{-1}$ and $\omega=2 \pi f$ is the angular frequency of the incident radiation with a frequency $f$ [21]. For the frequency range of 0.1 to $10 \mathrm{GHz}$ (Radarsat-2 has a carrier frequency of $5.405 \mathrm{GHz}$ ) the permittivity of sea water has a value of $60+40 j$ approximately and biogenic slicks have values between $2.2+$ $0.02 j-2.35+0.02 j$, approximately. As sea water becomes entrained in crude oil, the dielectric permittivity of the mixture can be expressed via a mixture model which relates the dielectric value of the oil-water mixture to the values for pure oil and pure sea water via the volumetric content of sea water present. This will be explained in greater detail in section IV.

In order for the SAR to detect the presence of surface films solely due to its dielectric properties, and not just the reduction of the small-scale surface roughness, the slick layer needs to be thick on the scale of the radar wavelength. This is due to the fact that radiation from the SAR will have a certain penetration depth [22]. Theory tells us that the presence of a monomolecular layer will be detectable solely due to the reduction in surface roughness, as the radar is able to penetrate through the substance, meaning the effective dielectric constant is that of water. The same principle holds for sheens of oil. Likewise, in "low wind" areas, with a reduction in wind induced capillary waves, dark patches are caused by a reduction in surface roughness and not changes in the dielectric constant.

Weathering refers to the processes that crude oils will undergo when released into the marine environment. Such processes include evaporation, emulsification, spreading, dissolution, dispersion, oxidation and biodegradation [23].

The slicks that are presented in this study were applied to the ocean environment and then subjected to the weathering processes discussed above. For all satellite acquisitions, the oils were present on the sea surface ranging from a few hours to a few tens of hours. The wind speeds were measured at or as close as possible to the times of satellite acquisitions. Due to the low wind speeds that were present, it is believed that emulsification and spreading, especially in the early stages of discharge, were the main natural factors in the evolution of the slicks over time with $90 \%$ of the oil is contained within $10 \%$ of the slick [24].

\section{Polarimetric Two-Scale Model}

Within the literature, there are numerous scattering models that are employed for modelling the backscatter from the ocean surface $[25,26,27,28]$. However, for the application study in our paper we will focus on the model presented in [16] denoted as the Polarimetric Two-Scale Model. The following section reviews the main characteristics of the PTSM which will be applied to the data outlined in section V. The model works on the assumption that the field scattered towards the sensor is mainly dependent on both the large- and small-scale roughness, and the dielectric constant of the scattering surface, implying that by using an appropriate inversion procedure, one should be able to invert for both of these parameters. In the following subsections a mathematical formulation is used to express the NRCS of backscattered radiation towards the SAR. 


\section{A. Surface Model}

The ocean surface here is considered to be composed of large-scale roughness variations with small-scale roughness variations superimposed onto it. This is the basic principle of the two-scale surface model approach. The large-scale roughness is modeled as being composed of slightly roughened, tilted facets whose slope is the same as that of a smoothed surface corresponding to the roughened facet. A condition for the use of such facets, is that the facets are greater in spatial extant than the wavelength of the incoming field, and also than that of the correlation length of the small-scale roughness, but also smaller than the spatial resolution of the sensor, and the correlation length of the large-scale roughness.

The small-scale roughness, $\delta(x, y)$, is modeled as a zeromean stochastic process where the height standard deviation $s$, is small when compared with the electromagnetic wavelength $\lambda$. In the model, it is assumed that $\delta(x, y)$ is a band-limited fractional Brownian motion (fBm) process (see e.g., [16] and the references therein) so that it has a power spectral density (PSD)

$$
W(K)=\frac{S_{0}}{K^{\left(2+2 H_{t}\right)}}=h^{2} \frac{S_{0 n}}{K^{\left(2+2 H_{t}\right)}}=s^{2} W_{n}(K)
$$

Where $K=\sqrt{K_{x}^{2}+K_{y}^{2}}$ and $K_{x}^{2}$ and $K_{y}^{2}$ are the Fourier mates of $x$ and $y$ respectively and $H_{t}$ is the Hurst coefficient, a quantity that is related to the fractal dimension $D$ by $D=3-H_{t}$ and has a value $0<H_{t}<1 . S_{0}$ is a quantity that is directly related to the roughness variance $h^{2}$ via the dimensional facet-sizedependent constant $S_{0_{n}}$ and $W_{n}(K)$ is the normalized power spectral density (PSD). According to [16] (and references therein), employing a description of the small-scale roughness as a $\mathrm{fBm}$ is appropriate as there is a wide consensus that $\mathrm{fBm}$ is an accurate model for natural surfaces.

In fractal analysis, the Euclidean concept of length is expressed as a process which is characterized by the fractal dimension parameter D [29]. For the case of the ocean surface, a value of $\mathrm{D}=2$ corresponds to a perfectly flat 2-dimensional surface with successively higher values of $\mathrm{D}$ corresponding to an increasingly roughened sea state. In [30] it is noted that valid values for $H_{t}$ for the ocean surface range from approximately 0.65 to 0.95 . In [16] it was demonstrated that the PTSM is only weakly dependant on the value of $H_{t}$. A value of 0.9 was selected in our study because only acquisitions acquired in lower wind speed range are included in this paper. This implies the ocean surface was not in an extremely roughened state.

\section{B. Single tilted-facet return}

Consider the sensor illuminating an area with at a specific incidence angle $v$ and where the field is scattered by a single titled rough facet. Due to the facet tilt, the angle between the incoming radiation and the normal to the tilted facet, referred to as the local incidence angle, denoted by $v_{l}$, will be different from the incidence angle and will be related to the facet slopes by

$$
\cos v_{l}=\frac{\cos v+b \sin v}{\sqrt{1+a^{2}+b^{2}}}
$$

The facet tilt also causes a rotation of the local incidence plane about the look direction $\hat{k}$ by an angle $\beta$ that is related to the facet slopes and to the incidence angle by

$$
\tan \beta=\frac{a}{-b \cos v+\sin v}
$$

Where $a=\tan (\omega)$, and $b=\tan (\gamma)$, are the facet slopes in the range and azimuth directions respectively and are assumed to be independent and identically distributed zero-mean $s^{2}$ variance Gaussian random variables i.e. $a, b \sim N\left(0, s^{2}\right)$.

The co-polarized NRCS for a single facet is derived in [16] and is given as

$$
\left\{\begin{array}{c}
\frac{4}{\pi} k^{4} \cos ^{4} v_{l} s^{2} W_{n}\left(2 k \sin v_{l}\right) \\
\sigma_{H H}^{0}=\mathrm{X}\left|F_{H}\left(v_{l}\right) \cos ^{2} \beta+F_{V}\left(v_{l}\right) \sin ^{2} \beta\right|^{2} \\
---- \\
\frac{4}{\pi} k^{4} \cos ^{4} v_{l} s^{2} W_{n}\left(2 k \sin v_{l}\right) \\
\sigma_{V V}^{0}=\mathrm{X}\left|F_{V}\left(v_{l}\right) \cos ^{2} \beta+F_{H}\left(v_{l}\right) \sin ^{2} \beta\right|^{2}
\end{array}\right.
$$

Where $F_{H}$ and $F_{V}$ are the Bragg coefficients, whos expressions can be found in [11].

The authors of [16] also include a discussion on the elements of the coherency matrix and the cross-polarization NRCS terms. As they are not directly relevant for this study they will not be discussed here and the reader is referred to that paper.

\section{Total Scattered Power}

If the large-scale-roughness height variations are larger than the incoming radiation wavelength and the facet size is larger than the small-scale-roughness correlation length, the returns from different individual facets are uncorrelated and the NRCS returns from the entire surface can be obtained by averaging that of a single facet over $\beta$ and $v_{l}$. As can be seen from equations (3), (4) and (5), the NRCS can be averaged over the facet slope distributions of $a$ and $b$, which as in [16], is assumed to be Normally distributed with a variance $s^{2}$. This is done via a Taylor series expansion and leads to a set of expressions for the co-polarization NRCS of an entire resolution cell given as

$$
\left\{\begin{array}{l}
\left\langle\sigma_{H H}^{0}\right\rangle_{/ a, b}=\frac{4}{\pi}\left[C_{0,0}^{H H}+\left[C_{2,0}^{H H}+2 \frac{\operatorname{Re}\left\{C_{0,0}^{H V}\right\}-C_{0,0}^{H H}}{\sin ^{2} v}+C_{0,2}^{H H}\right] s^{2}\right] \\
\left\langle\sigma_{V V}^{0}\right\rangle_{/ a, b}=\frac{4}{\pi}\left[C_{0,0}^{V V}+\left[C_{2,0}^{V V}+2 \frac{\operatorname{Re}\left\{C_{0,0}^{H V}\right\}-C_{0,0}^{V V}}{\sin ^{2} v}+C_{0,2}^{V V}\right] s^{2}\right]
\end{array}\right.
$$

where $s^{2}$ is a measure of the large-scale roughness. Here, the terms $C_{k, n-k}^{p q}$ are the series expansion coefficients of the function $\left(k \cos v_{l}\right)^{4} W F_{p} F_{q}^{*}$ and has the form 


$$
C_{k, n-k}^{p q}=\left.\frac{1}{n !}\left(\begin{array}{l}
n \\
k
\end{array}\right) \frac{\partial^{n}\left(\left(k \cos v_{l}\right)^{4} W F_{p} F_{q}^{*}\right)}{\partial a^{k} \partial b^{n-k}}\right|_{a=b=0}
$$

The full expressions for $C_{0,0}^{p q}, C_{2,0}^{p q}$ and $C_{0,2}^{p q}$ were derived numerically.

The equations displayed in (7) constitute the PTSM for the sake of this study. This model does not hold for small incidence angles in which geometrical optics contributions take over.

This model depends on the complex quantity $\varepsilon$. Given that inversion for $\varepsilon$ is computationally complex, the $\varepsilon$ parameter is assumed to be a real valued variable with a value equal to $|\varepsilon|$. As is common practice when attempting to determine the permittivity of wet soils, $\varepsilon$ is assumed to have a value equal to $|\varepsilon|[15,16]$. This is a valid assumption as the imaginary part of $\varepsilon$ is not-dominant for lower values. When determining the permittivity of marine scattering targets the imaginary part of $\varepsilon$ becomes more relevant. A discussion on the error incurred by making this alteration is discussed in Appendix A.

\section{INVERSION FOR THE DIELECTRIC CONSTANT}

As the volumetric water content of the oil affects its dielectric value, it is possible to estimate the dielectric value of the scattering substance by employing an appropriate mixing model that is available in the literature $[12,31]$. The mixture model that is chosen in this study is known as the linear mixture model and is given by

$$
\varepsilon_{e m}=\varepsilon_{s w}+v_{o i l}\left(\varepsilon_{o i l}-\varepsilon_{s w}\right)
$$

Where $\varepsilon_{S W}$ is the dielectric constant of pure sea water, $\varepsilon_{o i l}$ is the dielectric constant of pure oil and $v_{\text {oil }}$ denotes the volume fraction of oil in the emulsion.

Skrunes et. al. [23] conducted a noise analysis of the quadpolarimetric SAR data presented in this study and found that the co-pol channels are susceptible to internal system noise, especially at higher incidence angles. Before inversion, a noise estimation procedure was implemented and is based on the method presented in [32]. The retrieved noise values were subtracted from the data before further processing was performed.

\section{A. The co-pol Method and Model Assumptions}

The polarization ratios for the NRCS are defined as

$$
\left\{\begin{array}{c}
\text { Co }-p o l=\frac{\left\langle\sigma_{V V}^{0}\right\rangle_{/ a, b}}{\left\langle\sigma_{H H}^{0}\right\rangle_{/ a, b}} \\
\text { Cross }- \text { pol }=\frac{\left\langle\sigma_{H V}^{0}\right\rangle_{/ a, b}}{\left\langle\sigma_{V V}^{0}\right\rangle_{/ a, b}}
\end{array}\right.
$$

The benefit of using the polarimetric ratios, as described in (9), is that the dependence on the small-scale roughness descriptor is removed.

The only significant parameters that the polarization ratios depend on are the large-scale-roughness descriptor, $\mathrm{s}$, and the relative permittivity, $\varepsilon$. In [16], both the co- and cross-pol ratios are utilized in order to perform an inversion for $\varepsilon$. However, as is generally known, the backscatter return from areas of oil slick can be minimal in the cross-polarization channels. For this reason, only the co-pol ratio will be considered further. Fig. 1 shows the PTSM co-pol ratio plotted against $|\varepsilon|$ at an incidence angle of $45^{\circ}$ and a $H_{t}$ of 0.9 . This graph shows the dependence of the model on $s$ and illustrates that the PTSM is highly sensitive to values of $s$. As can be seen also from this graph, the PTSM is highly insensitive to $|\varepsilon|$ values over 30 approximatly.

This high sensitivity indicates that $s$ needs to be estimated locally. In order to estimate $s$, it is noted that the co-polarization ratio image has a gaussian distribution over ocean areas. Using typical inputs for the temperature and salinity of the North Sea, a value for $\varepsilon$ of the open ocean in C-band was found to be approximately $65.54-37.33 \mathrm{j}$, equating to a value for $|\varepsilon|$ of 75.43. This is consistent with [33] who determined the complex dielectric constant of sea water at $0^{\circ} \mathrm{C}$ and a salinity of $35 \mathrm{ppt}$ to be $64-40 \mathrm{j}$.

The co-polarization ratio image is then divided into square regions of size $100 \times 100$ pixels. The $s$ value for which the model curve approximates the mean of the co-polarization ratio scatter data at a value of $|\varepsilon|$ equating to 75.43 is taken to be the estimate for $s$, see Fig.2. The value of the incidence angle for the centre of each specific $100 \times 100$ pixel region is used as an input for that variable.

After the $s$ value for each square $100 \times 100$ pixel region is found, the oil infested areas are manually masked out and inward interpolation is performed to try to determine an estimate for $s$ within the slick. The assumption that is made is that surface slick will only dampen the short-scale surface roughness and not the large-scale roughness leading to similar values for $s$ both within and outside the slick.

As an example, the scatter of co-polarization ratio values within a single 100 pixel $\times 100$ pixel sized image portion is shown in Fig. 2 and is represented as the red, vertical scatter and is plotted at a value of $|\varepsilon|$ of 75.43 . The average of the

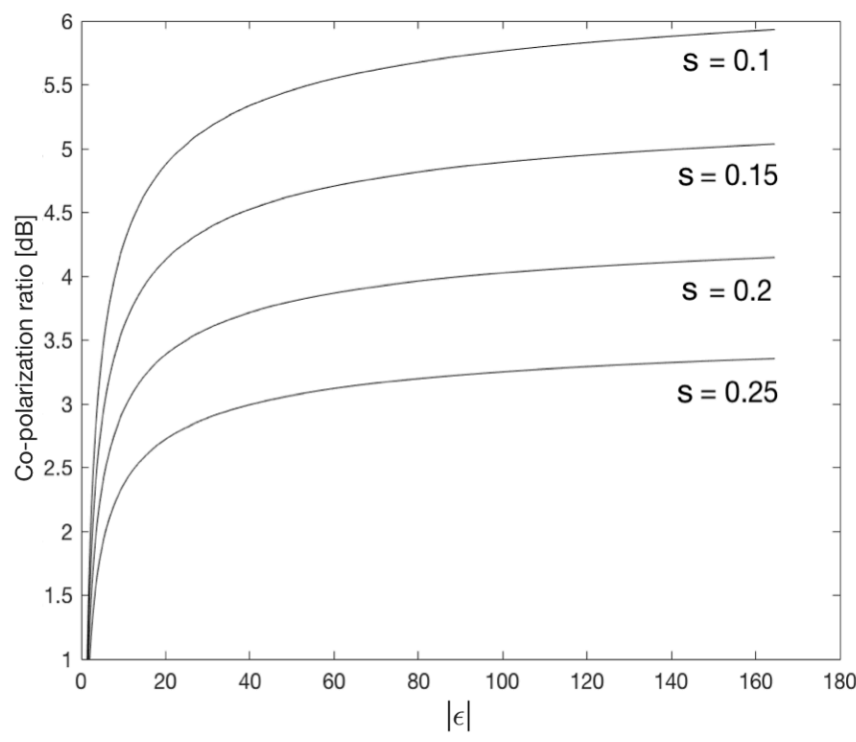

Fig. 1: PTSM curves computed for various values of $s$ at $40^{\circ}$ incidence angle, $H_{t}=0.9$ and radiation frequency of $5.4 \mathrm{GHz}$. The models sensitivity to $\sigma$ is apparent. 
scatter is shown as a blue $\mathrm{X}$. As can be seen, the $\mathrm{X}$ is overlaid on the model curve. The value of $s$ for which the $\mathrm{X}$ and the PTSM curve converge is chosen as the $s$ estimate for that copolarimetric image portion.

When the $s$ value has been determined, the co-polarimetric image is converted to $|\varepsilon|$ via a look-up table approach i.e. the value of $|\varepsilon|$ which minimizes the following

$$
\| \text { copol }_{\text {from data }}-\text { copol }_{\text {from theory }} \|
$$

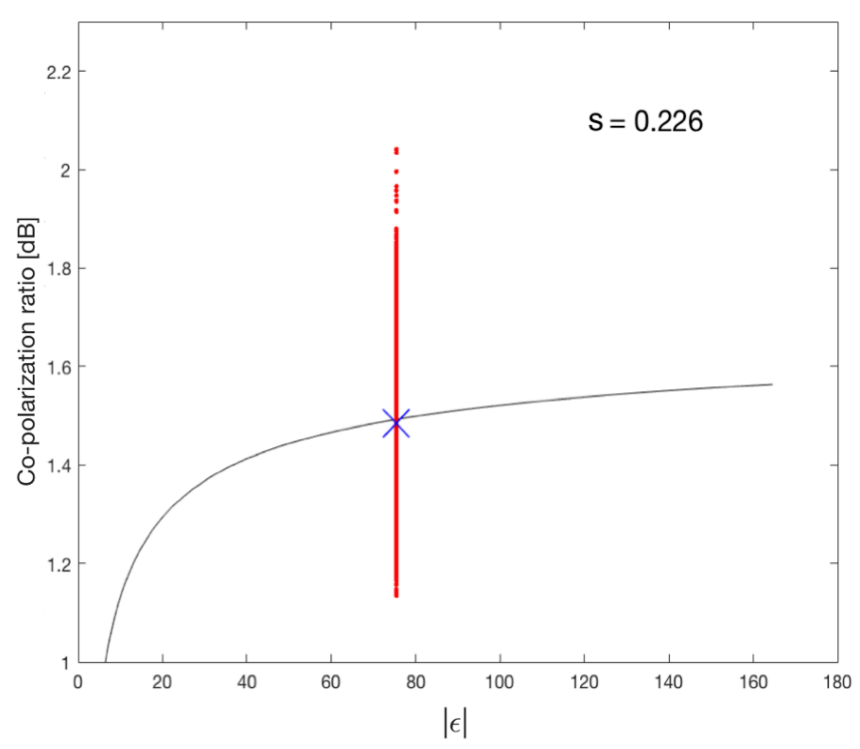

Fig. 2: Method for estimating $s$. The red line is a scatter of points taken from a 100 pixel $\times 100$ pixel sized portion of the copol image over clean ocean. The blue $\mathrm{X}$ is the mean of these pixel values. The $s$ value for which the PTSM curve coincides with the blue $\mathrm{X}$ at the $|\varepsilon|$ value for water is assumed to be a valid estimation for $s$. The incidence angle here is approximately $30^{\circ}$.

The areas that correspond to oil slick are estimated in the same way but were first masked out. Interpolation is performed on the masked-out regions in order to determine what $s$ would be for the oil infested portions of the image. The assumption that is made here is that areas that are side-by-side have similar $s$ values.

\section{EXPERIMENTAL SETUP AND DATA ACQUISITION}

NOFO conducts an annual oil-on-water exercise in the North Sea (N 59 59', E $\left.2^{\circ} 27^{\prime}\right)$. During these exercises, controlled discharges of oil are used to test clean-up methods and to test response procedures. The exercise provides a unique opportunity to acquire SAR imagery of verified mineral oil and plant oil slicks in juxtaposition. In some cases, the releases were subjected to mechanical recovery and dispersion before the SAR imagery was acquired. The data sets that are presented in the following subsections correspond to oil-on-water exercises for the years 2011, 2012 and 2013. All data were acquired by Radarsat-2 in fine quad-polarization mode. Four data sets are used throughout this study. Two data sets correspond to cleanup exercises conducted in 2011, one in 2012 and one in 2013. The acquisitions were taken at different times of the day corresponding to the overpass of Radarsat-2s sun-synchronous orbit. As a consequence, the acquisitions were taken either early in the morning or late in the afternoon. In order to easily reference the imagery throughout the rest of the paper each scene will be referred to by the year it was acquired followed by either a ' $m$ ' or an ' $e$ ', indicating whether the scene was acquired in the morning or evening respectively.

\section{A. Overview of acquisitions}

Four C-band Radarsat-2 Fine quad polarization acquisitions are presented in this study. Table 1 provides a complete overview of all acquisitions. Table 1 also displays wind speed data that were taken by ships participating in the exercises as well as data taken from a nearby oil platform. There is a difference in time and space between the acquisition of the wind speed data and the acquisition of the SAR data, however large deviations from these measurements are not expected.

Fig. 3 (a) and (b) shows the 9x9 multi-looked VV intensity channels over the regions where oil slick was observed, with the slick types identified in the images. The slick to the left seen in $2011 \mathrm{~m}$ is the Plant oil, which was released $\sim 2$ hours before the acquisition while the slick to the right, the slick of emulsion, was released $\sim 18$ hours prior to the satellite pass. 2011e shows the plant oil slick occupying the left most part of the image, which was released $\sim 15$ hours prior to image acquisition, the center slick shows emulsion which was released $\sim 29$ hours prior to acquisition, and the right most slick shows crude oil which was released $\sim 8$ hours prior to acquisition. Chemical dispersion of the crude oil was ongoing while the scene was being acquired. Ships are seen as bright points in both images.

Fig. 3 (c) shows, 2012m, a VV 9x9 multilooked Radarsat-2 quad polarization acquisition taken on $15^{\text {th }}$ June 2012 . The scene shows a single slick of plant oil in the upper left of the scene and three slicks of emulsion positioned in the center of the image orientated from top to bottom.

The plant oil was released $\sim 14$ hours prior to acquisition while the slicks of emulsion $\mathrm{a}, \mathrm{b}$ and $\mathrm{c}$ were released $\sim 14,17$ and 22 hours prior to acquisition, respectively.

Fig. 3 (d) shows 2013e which was acquired $11^{\text {th }}$ June 2013. Two slicks can be seen within the image. One of plant oil which was released $\sim 3$ hours prior to acquisition and the other of emulsion which was released $\sim 1$ hour prior to acquisition.

Table 2 provides an overview of the relevant information relating to these slicks as well as outlining some of the process they were subjected to.

Table 1: Properties of SAR acquisitions 2011m and 2011e [23]. Properties of SAR scenes for $2012 \mathrm{~m}$ and 2013e acquisitions [22], [34].

\begin{tabular}{|c|c|c|c|c|}
\hline Scene ID & 2011m & 2011e & 2012m & 2013e \\
\hline Date & 8 June 2011 & 8 June 2011 & $\begin{array}{c}15 \text { June } \\
2012\end{array}$ & $\begin{array}{c}11 \text { June } \\
2013\end{array}$ \\
\hline Time (UTC) & $05: 59$ & $17: 27$ & $06: 20$ & $17: 18$ \\
\hline Mode & Fine Quad. & Fine Quad. & Fine Quad. & Fine Quad. \\
\hline $\begin{array}{c}\text { Incidence } \\
\text { angle }\end{array}$ & $46.1^{\circ}-47.3^{\circ}$ & $34.5^{\circ}-36.1^{\circ}$ & $\begin{array}{c}30.3^{\circ}- \\
32.0^{\circ}\end{array}$ & $\begin{array}{c}28.1^{\circ}- \\
29.9^{\circ}\end{array}$ \\
\hline $\begin{array}{c}\text { Resolution } \\
\text { (Rg x Az) [m] }\end{array}$ & $5.2 \times 7.6^{*}$ & $5.2 \times 7.6^{*}$ & $5.2 \times 7.6^{*}$ & $5.2 \times 7.6^{*}$ \\
\hline $\begin{array}{c}\text { Pixel spacing } \\
\text { (Rg x Az) [m] }\end{array}$ & $4.7 \times 4.7$ & $4.7 \times 4.8$ & $4.73 \times 5.6$ & $4.7 \times 4.8$ \\
\hline Wind speed & $1.6-3.3 \mathrm{~m} / \mathrm{s}$ & $1.6-3.3 \mathrm{~m} / \mathrm{s}$ & $4 \mathrm{~m} / \mathrm{s}$ & $5 \mathrm{~m} / \mathrm{s}$ \\
\hline
\end{tabular}


Table 2: Properties of discharged slicks in $2011 \mathrm{~m}, 2011 \mathrm{e}, 2012 \mathrm{~m}$ and $2013 \mathrm{e}$ at time of release and operations performed in the interim between discharge and satellite acquisitions. The age of the slicks as seen within the SAR acquisitions are also shown. Taken from [22], [23], [34] and [36].

\begin{tabular}{|c|c|c|c|c|}
\hline & $\begin{array}{c}\text { Date } \\
\text { (time of } \\
\text { release) }\end{array}$ & $\begin{array}{l}\text { Vol. } \\
\left(\mathrm{m}^{3}\right)\end{array}$ & Subjected to & $\begin{array}{c}\text { Age } \\
\text { [hours] }\end{array}$ \\
\hline $\begin{array}{c}\text { Emulsion } \\
(2011 \mathrm{~m} / \mathbf{2 0 1 1 e})\end{array}$ & $\begin{array}{c}7 \text { June } 2011 \\
12: 15\end{array}$ & 20 & $\begin{array}{c}\text { Mechanical } \\
\text { recovery } \\
\left(\sim 1 \mathrm{~m}^{3} \text { left on }\right. \\
\text { surface })\end{array}$ & $18 / 29$ \\
\hline $\begin{array}{c}\text { Plant oil } \\
(2011 \mathrm{~m} / 2011 \mathrm{e})\end{array}$ & $\begin{array}{c}\text { 8 June } 2011 \\
04: 10\end{array}$ & 0.4 & Untouched & $2 / 13$ \\
\hline $\begin{array}{c}\text { Crude oil } \\
(2011 \mathrm{~m} / 2011 \mathrm{e})\end{array}$ & $\begin{array}{c}8 \text { June } 2011 \\
08: 23\end{array}$ & 30 & $\begin{array}{l}\text { Dispersion (on- } \\
\text { going) }\end{array}$ & $\mathrm{n} / \mathrm{a} / 9$ \\
\hline $\begin{array}{c}\text { Emulsion a } \\
(2012 \mathrm{~m})\end{array}$ & $\begin{array}{c}\text { 14 June } 2012 \\
\text { N/A }\end{array}$ & 14 & $\begin{array}{c}\text { Mechanical } \\
\text { recovery } \\
\left(\sim 12 \mathrm{~m}^{3} \text { left on }\right. \\
\text { surface })\end{array}$ & 14 \\
\hline $\begin{array}{c}\text { Emulsion b } \\
(2012 \mathrm{~m})\end{array}$ & $\begin{array}{c}14 \text { June } 2012 \\
\text { N/A }\end{array}$ & 17 & $\begin{array}{c}\text { Mechanical } \\
\text { recovery } \\
\left(\sim 7 \mathrm{~m}^{3} \text { left on }\right. \\
\text { surface })\end{array}$ & 17 \\
\hline $\begin{array}{c}\text { Emulsion c } \\
(2012 \mathrm{~m})\end{array}$ & $\begin{array}{c}14 \text { June } 2012 \\
\text { N/A }\end{array}$ & 10 & $\begin{array}{c}\text { Mechanical } \\
\text { recovery } \\
\left(\sim 4.8 \mathrm{~m}^{3} \text { left on }\right. \\
\text { surface })\end{array}$ & 22 \\
\hline $\begin{array}{l}\text { Plant oil } \\
(2012 \mathrm{~m}) \\
\end{array}$ & $\begin{array}{c}\text { 14 June } 2012 \\
\text { N/A }\end{array}$ & 0.4 & Untouched & 14 \\
\hline $\begin{array}{c}\text { Emulsion } \\
\text { (2013e) }\end{array}$ & $\begin{array}{c}11 \text { June } 2013 \\
06: 00\end{array}$ & 50 & $\begin{array}{c}\text { Mechanical } \\
\text { recovery } \\
\left(\sim 14 \mathrm{~m}^{3} \text { left on }\right. \\
\text { surface })\end{array}$ & 1 \\
\hline Plant oil (2013e) & $\begin{array}{c}11 \text { June } 2013 \\
14: 00\end{array}$ & 0.4 & Untouched & 3.5 \\
\hline
\end{tabular}

\section{INVERSION RESULTS}

\section{A. Overview of results}

The following section shows the results of the inversion procedure outlined in the previous sections on the SAR data. The model was allowed to run for values of $|\varepsilon|$ ranging from 0.5 to 165 approximately. The lower limit of 0.5 was chosen as it was noticed that some pixels would have been inverted to $|\varepsilon|$ values below the theoretical $|\varepsilon|$ value of pure oil, i.e. 2.3. The upper limit of 165 is an arbitrarily high value that was chosen so as to highlight the models insensitivity to high values of $|\varepsilon|$, this can be seen in Fig. 2, and so as not to mislead the reader into thinking that a definitive value for $|\varepsilon|$ over open water can be obtained. Fig. 2 highlights this by showing that the scatter that lies above the model curve will have values ranging from 75.43 up until the upper limit of 165 . The following images were thresholded at values of $|\varepsilon|$ of 21 . The value of 21 was manually estimated by taking various transects along the inverted $|\varepsilon|$ images of the oil slicks. These transects contained $|\varepsilon|$ values from within the oil slick and the open water. It was consistently noted within all inverted images that the edges of the slicks tended to obtain values of $|\varepsilon|$ ranging between 2022. In the following results, the sea is thresholded out in order to highlight the internal variation of $|\varepsilon|$ within the oil slick. Examples of $|\varepsilon|$ where the surrounding ocean is not thresholded can be seen in Fig. 9 (b) and (d).

As can be seen, when comparing the slick filled areas that manifest themselves as dark patches in the SAR images of Fig. 3 and the imagery of the inversion results shown in Fig.4,5,7 and
8 the oil slicks appear to have retained the same shape after inversion, suggesting that the model is able to easily differentiate between open ocean and slick filled areas. An exception to this are the slicks of plant oil in $2011 \mathrm{~m}$ and emulsion in 2011e. As can be seen when comparing the images of these slicks and seen in Fig. 3 (a) and Fig. 3 (b) with their inversion results shown in Fig.4 (c) and Fig. 4 (b) respectively, certain areas of the slick are eroded away in the resulting $|\varepsilon|$ images. This is a result of some parts of these slicks showing little contrast between the open ocean within the copolarimetric ratio imagery. This is most likely a result of those portions of the slick being thin enough to allow the incoming radiation of be modified solely by the underlying ocean. This will be highlighted again in section VII.E.

The surrounding ocean areas appear to be a cluttered ensemble of randomly assorted $|\varepsilon|$ values spanning the full range of values the model was allowed to run for, which can be seen in the unthresholded inversion results of Fig. 9. This is to be expected as explained in the previous section, the copolarization values over open ocean have a Gaussian like distribution, with a certain spread, and so will span the entirety of the applied model curve.

As can be seen in the images in Figs. 4,5,7 and 8 all slicks appear to contain internal zones with varying values of $|\varepsilon|$. It is believed that areas of $|\varepsilon|$ that are lower in value within the slicks of crude oil and emulsion, contain greater concentrations of oil then areas of higher values. All areas containing ships have been masked out in the inverted images and all inverted images have been thresholded at a value for $|\varepsilon|$ of 21 . Thresholding was performed to highlight the dynamic range of $|\varepsilon|$ values within slick. This step is necessary as pixels outside slick have values of $|\varepsilon|$ ranging from approximately 20-22 up to 165 . Any small clusters of low values of $|\varepsilon|$, i.e. values of 20-22, outside the slicks that are clearly areas of ocean, were eroded away.

In the following subsections the inversion results will be discussed as follows, first the results from the 2011 campaign will be discussed followed by the results from the 2012 campaign then followed by the results from the 2013 campaign. The section will conclude with a brief discussion on miscellaneous observations related to the inversion results.

\section{B. Inversion results: 2011 campaign}

The results obtained from the 2011 campaign offer a unique opportunity to examine the model effectiveness for two data sets that were acquired approximately 12 hours apart, under the same wind conditions, but under different incidence angles and at different times in the slicks evolution.

The crude oil was discharged 2 hours after the $2011 \mathrm{~m}$ scene was acquired and so is particular only to the 2011e scene. The water-in-oil emulsion in $2011 \mathrm{~m}$, was 18 hours old and had a volume of $20 \mathrm{~m}^{3}$. Between SAR acquisitions, the emulsion was subject to mechanical recovery which resulted in approximately $1 \mathrm{~m}^{3}$ being left on the surface and subsequently imaged. This can be seen in the difference in special extent between the slicks in Fig. 4 (a) and (b). Fig. 4 (e) and (f) show the normalized histograms for the 3 slick types that are considered in the 2011 campaign. The histograms for the emulsions are similar in that they both have peaks around the theoretical value of $|\varepsilon|$ for pure mineral oil, i.e. 2.3 , with the 


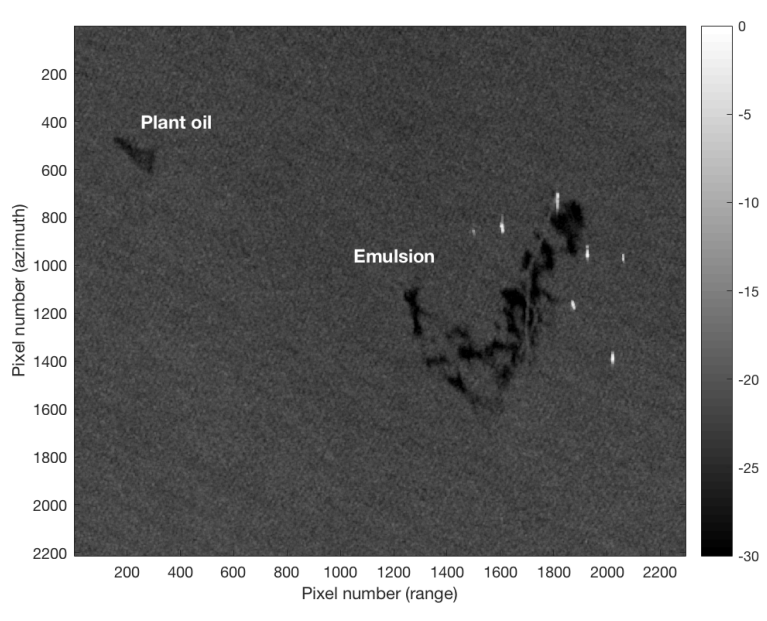

(a) Radarsat-2 scene 8 June 2011, 05:59 UTC (2011m).

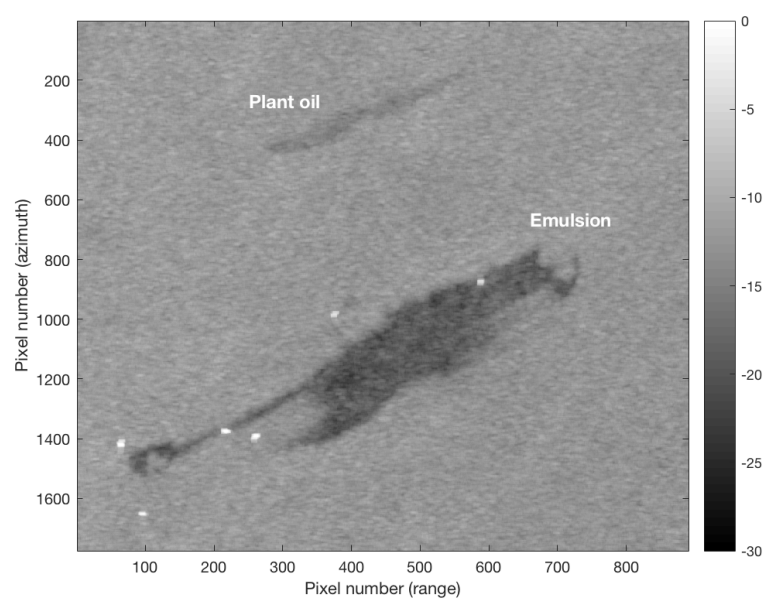

(c) Radarsat-2 scene 11 June 2013, 17:18 UTC (2013e).

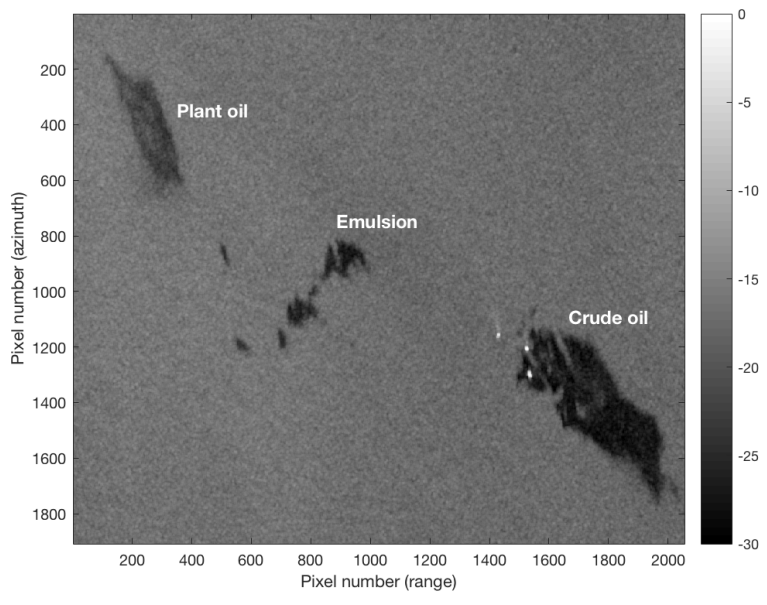

(b) Radarsat-2 scene 8 June 2011, 17:27 UTC (2011e).

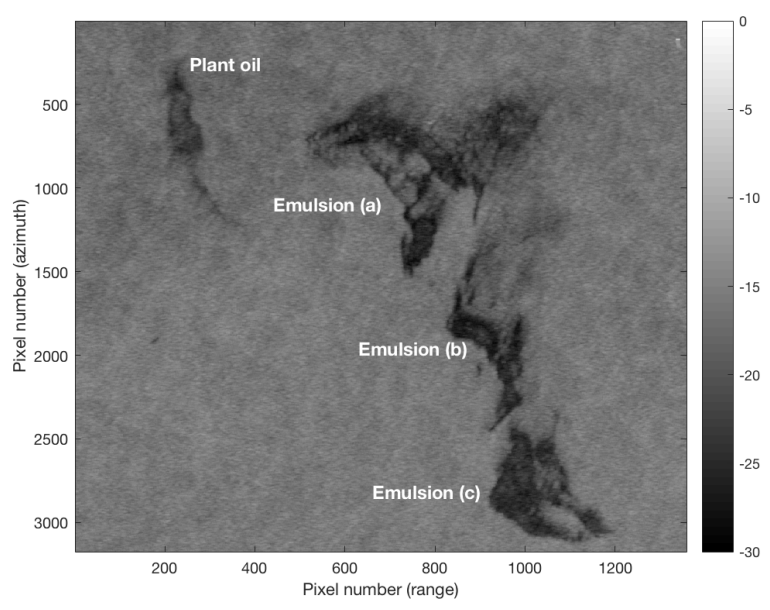

(d) Radarsat-2 scene 15 June 2012, 06:20 UTC (2012m).

Fig. 3: Intensity images $\left(\sigma_{V V}^{0}[d B]\right)$, multi-looked by $9 \times 9$ window.

distributions having successively lower quantities for higher values of $|\varepsilon|$.

The plant oil had a volume of $0.4 \mathrm{~m}^{3}$ and was untouched between SAR acquisitions. As can be seen in the images contained in Fig. 4 (c) and (d), the spatial extent of the plant oil in the $2011 \mathrm{~m}$ scene was much less in extent than the $2011 \mathrm{e}$ scene. At the time of acquisition of the $2011 \mathrm{~m}$ scene, the plant oil was 2 hours old while in the 2011e scene the oil was 13 hours old. The clear implication is that spreading/mixing into the water column occurred in the interim.

The normalized histograms in Fig. 4 (e) and (f) show that the two plant oil slicks have different distributions. The distribution from the $2011 \mathrm{~m}$ scene can only be described as having an irregular shape, while the slick in the 2011e scene has a regular Rayleigh like distribution. According to the literature the plant oil which has ambiphylic/ambiphobic structure should form a monotonic surface layer which should be transparent to the incoming radiation from the sensor [37]. However, some studies $[38,39,40]$ suggest that surface dwelling slicks, may undergo mixing into the water column due to the presence of wind and wave action. A possible explanation for the discrepancy between the two histograms is that when $2011 \mathrm{~m}$ was acquired, the plant oil may have existed as a quasi-surface film that was partially mixed into the water column. By the time $2011 \mathrm{e}$ was imaged, the oil may have mixed sufficiently into the water column that is was imaged as a scattering target with an effective thickness larger than that of a monomolecular layer.

The crude oil slick, shown in Fig. 5, was undergoing dispersion and had a volume of $30 \mathrm{~m}^{3}$ at the time of acquisition. The normalized histogram for this slick has a regular Rayleighlike distribution with a peak at slightly less than 2 . As can be seen in this histogram, a significant number of pixels within the slick have low values for $|\varepsilon|$ that have values close to the theoretically expected value of approximately 2.3 . This can be seen below in Fig. 5.

Within all slicks, clearly defined internal zones can be seen which are surrounded by successively higher values of $|\varepsilon|$. It is believed that these internal zones correspond to areas there are greater concentrations of oil are present compared to other areas of the slick.

\section{Inversion results: 2012 campaign}

Four slicks can be seen in the $2012 \mathrm{~m}$ scene of Fig. 3 (c). One of plant oil and 3 of emulsions. The age of all slicks were 14, 


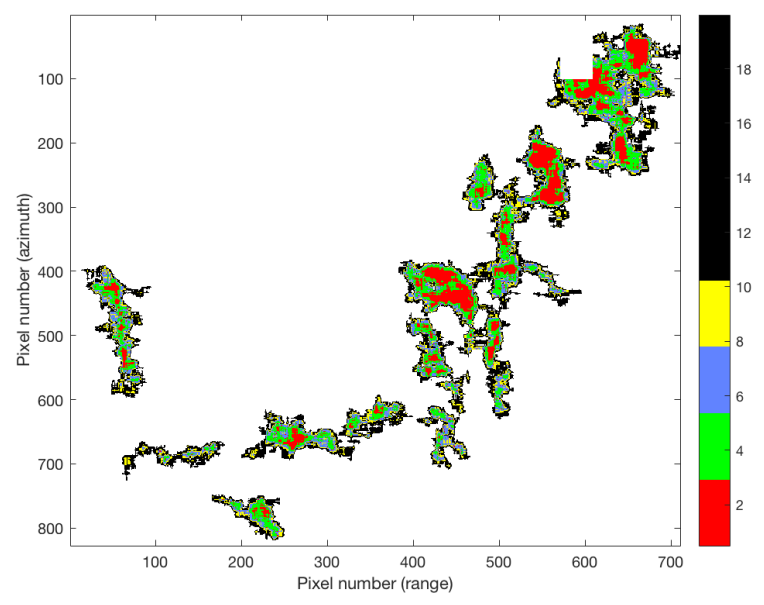

(a) Inversion result for slick of emulsion in $2011 \mathrm{~m}$

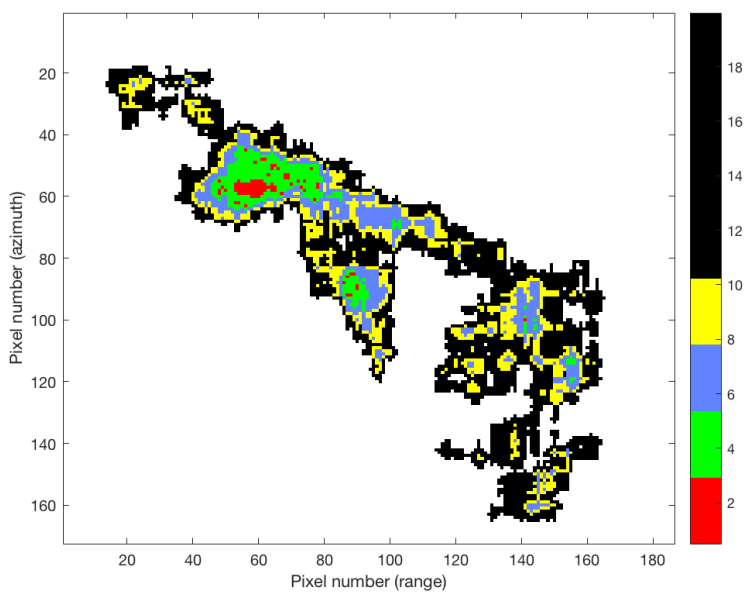

(c) Inversion result for plant oil slick in $2011 \mathrm{~m}$

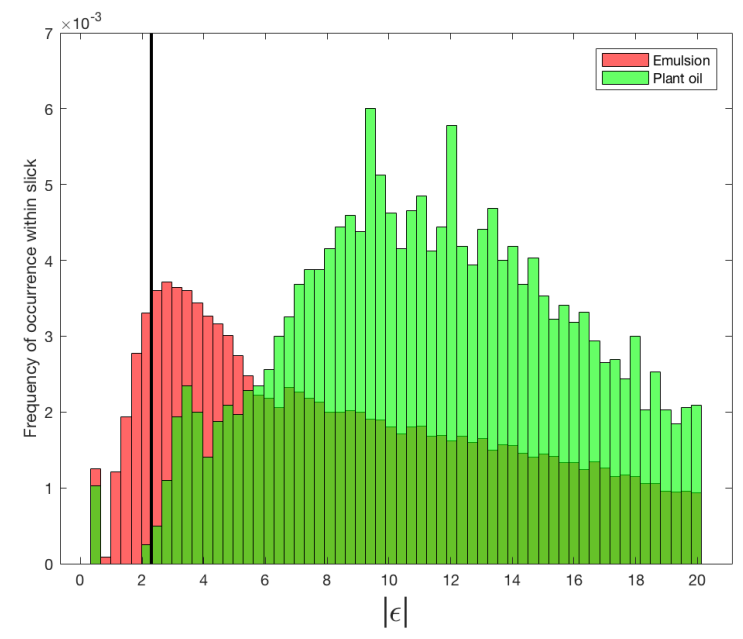

(e) Normalized histograms of $|\varepsilon|$ for slicks in (a) and (c).

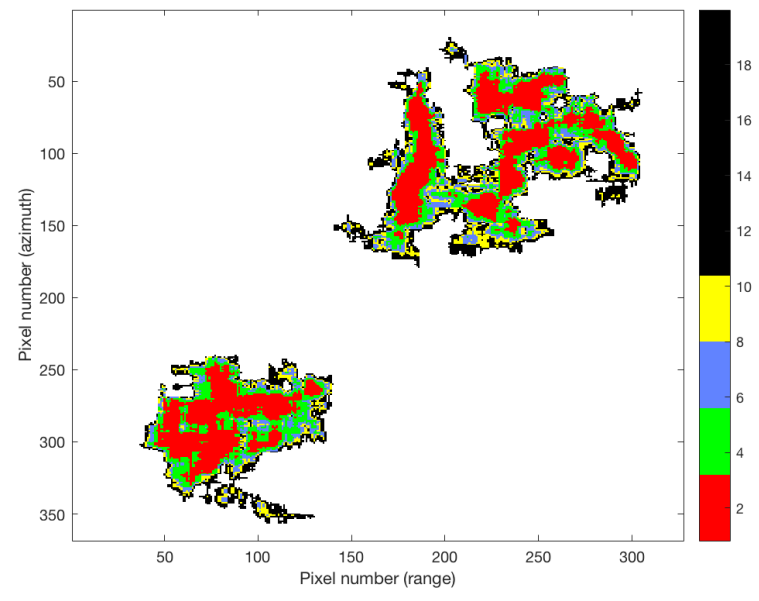

(b) Inversion result for slick of emulsion in $2011 \mathrm{e}$

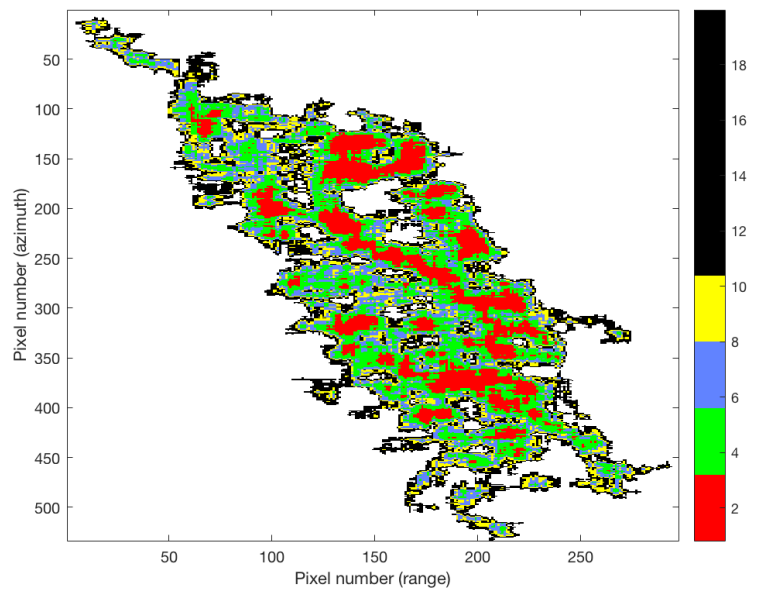

(d) Inversion result for plant oil slick in $2011 \mathrm{e}$

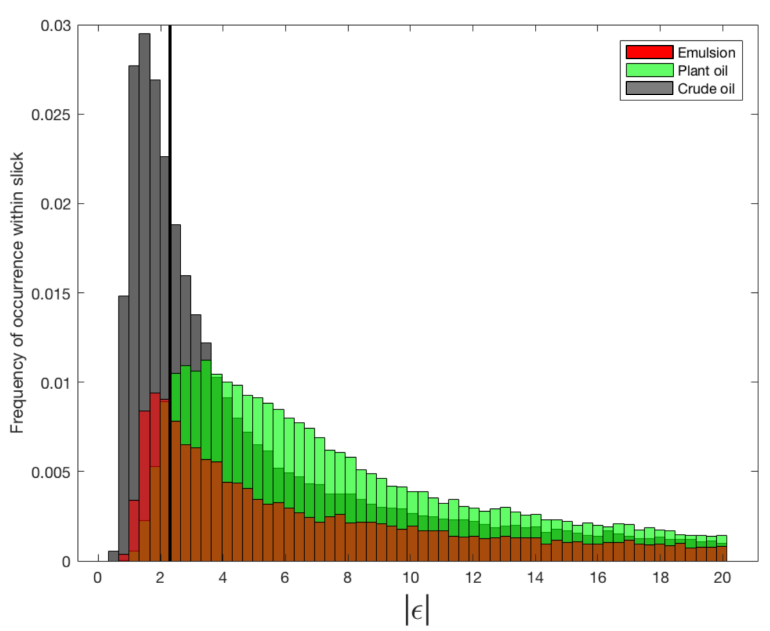

(f) Normalized histograms of $|\varepsilon|$ for slicks in (b) and (d)

Fig. 4: (a)-(d) inversion results for the slicks of emulsion and plant oil contained within $2011 \mathrm{~m}$ and 2011e. (e) normalized histograms for the slicks contained in (a) and (c), (f) normalized histograms for slicks contained in (b) and (d) as well as the crude oil slick contained in Fig. 5. The vertical line indicates the $|\varepsilon|$ value for pure oil, i.e. approximately $2.3[16]$ and is inserted for reference. 


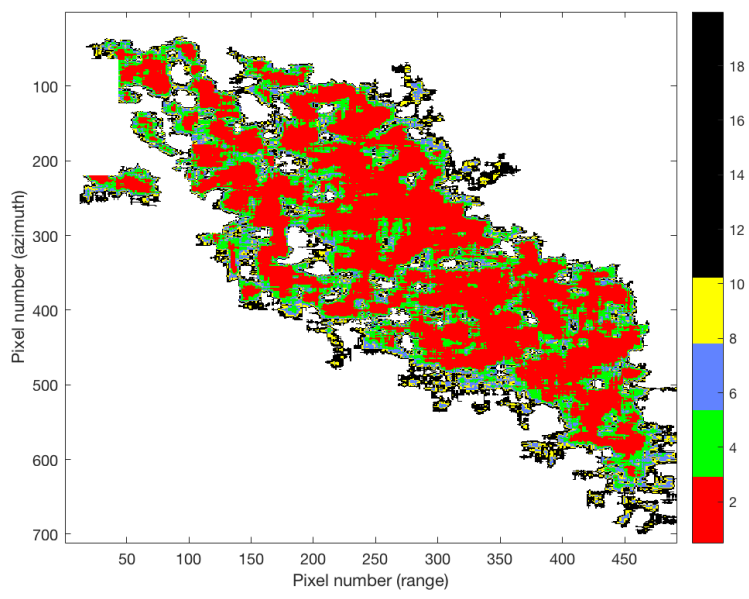

Fig. 5: Inversion result for Crude oil slick from 2011e.

17 and 22 hours for slicks of emulsions $\mathrm{a}, \mathrm{b}$ and $\mathrm{c}$ respectively and 14 hours for the slick of plant oil. Fig. 7 shows the thresholded inversion results for the slicks of plant oil and emulsions a-c. Fig. 6 shows the normalized histograms for all slicks.

A notable aspect of this histogram is that all slicks have the same type of distribution, i.e. the Rayleigh like distribution that is typical for most of the slicks in the previous section. It can be seen though that the histogram for the plant oil shows a higher expectation value than the three slicks of emulsion. The interesting aspect about this data set is that all slicks are comparable in age. In fact, the slick of emulsion a and the plant oil are the same age.

As can be seen from the histograms of the inversion results of the emulsions in Fig 6, the slicks of emulsion have similar $|\varepsilon|$ values to the slicks of emulsion contained in the previous section. A contrast can be seen when these slicks of emulsion are compared to the crude oil slick in the previous section which had a high number of pixels with lower $|\varepsilon|$ values.

As mentioned in the previous section it is believed that the primary process that is responsible for the values of $|\varepsilon|$ within the slick of emulsion is due to emulsification whereas the primary mechanism responsible for $|\varepsilon|$ values within the plant oil slick are due to mixing into the water column.

\section{Inversion results: 2013 campaign}

The composition of the emulsion present in the 2013e scene is similar in composition to that used during the 2011 campaign. At the time of acquisition, the slick was approximately 1 hour old. The histogram in Fig. 8 (b) shows that even at an age of 1 hour, the distribution of $|\varepsilon|$ tends to assume a Rayleigh like distribution, the same as the slicks of emulsions present in the 2011 and 2012 campaigns. As in the previous section the black vertical line marks the value of $|\varepsilon|$ for pure crude oil, i.e. 2.3 and was inserted for reference.

As can be seen in Fig. 3 (d) the plant oil is clearly defined in the SAR image but was not clearly defined in the inverted image. A possible reason for this is that at the time of acquisition the plant oil is only 3 hours old and may not have become mixed into the water column but instead may have still remained at the ocean surface as a mono-molecular layer. As a mono-molecular would be effectively invisible to the sensor, the inverted region would be practically indistinguishable to the surrounding ocean areas. For this reason, the plant oil in this section will not be discussed further.

The slick of emulsion is 1 hour old and was subjected to mechanical recovery before acquisition. As can be seen from the histogram in Fig. 8 (b), the expectation values are higher than for the crude oil slick in Fig. 4 (f) and are typical of the values that can be seen for other slicks of emulsions in the histograms of Fig. 4 (e), (f) and Fig. 6. In contrast to the histogram of the crude oil slick of Fig. 4 (f) few pixels of very low $|\varepsilon|$ values appear to be seen.

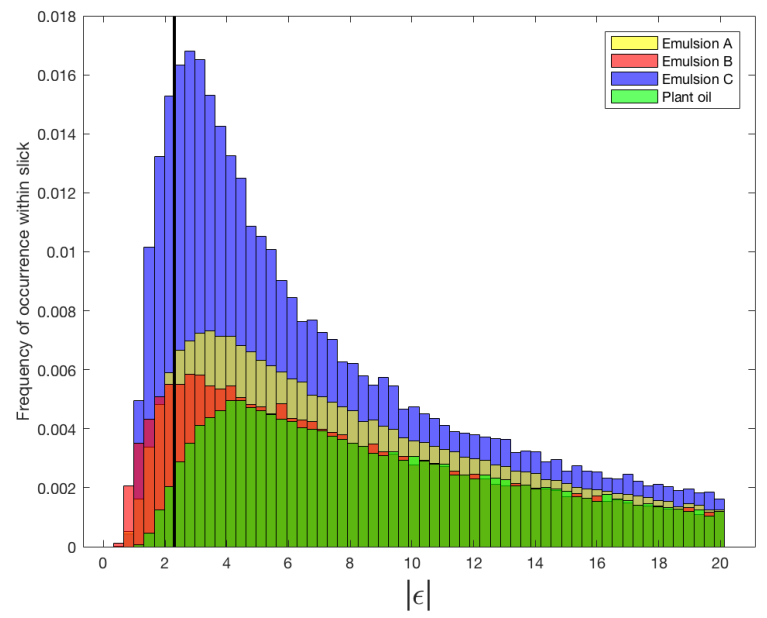

Fig. 6: Normalized histograms for the slicks contained in $2012 \mathrm{~m}$. The vertical line indicates $|\varepsilon|$ for pure oil and is inserted for reference.

\section{E. Anomalous observations}

As stated in previous sections, the areas of open ocean that were in close proximity to the slicks were used to estimate the roughness parameter $\mathrm{s}$ for the slick filled areas. This was necessary as the cross-pol channels were unavailable due to the high level of noise present. As well as this, it is demonstrated that the PTSM in the form of solely the co-pol channels are highly sensitive to values of $\mathrm{s}$. The method that was adopted in order to estimate the s parameter is outlined in the previous sections.

It is noticed that in the inversion results there are a number of artifacts of interest that need to be addressed. The images shown below in Fig. 9 show the full acquisitions of $2011 \mathrm{~m}$ and a portion of $2012 \mathrm{~m}$ as well as their inversion results.

The portion of the $2012 \mathrm{~m}$ data set shows emulsion $\mathrm{b}$. The main body of the slick can be seen as a dark patch while lighter areas are believed to be areas of sheen. Areas that are whitish in appearance are open water. The inverted image shows the non-thresholded inversion result. As can be seen, only the areas that correspond to the thicker emulsions are inverted while the areas that correspond to sheen become indistinguishable from the surrounding ocean. This result is theoretically to be expected as sheen presents a scattering surface that is sufficiently thin to allow radiation to be modified solely by the 


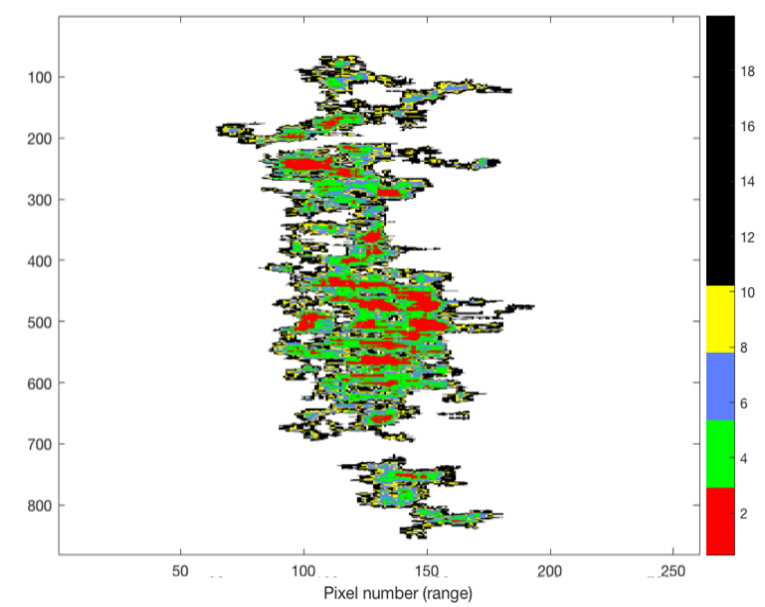

(a) Plant oil

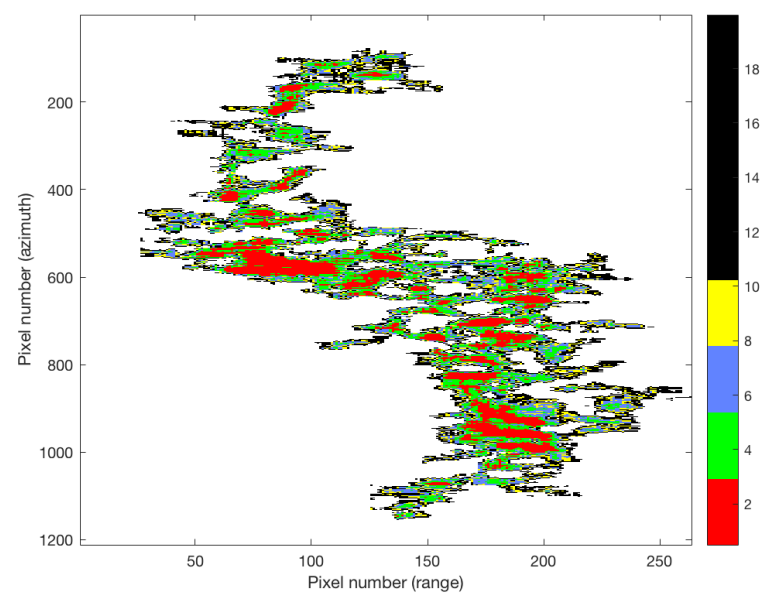

(c) emulsion b

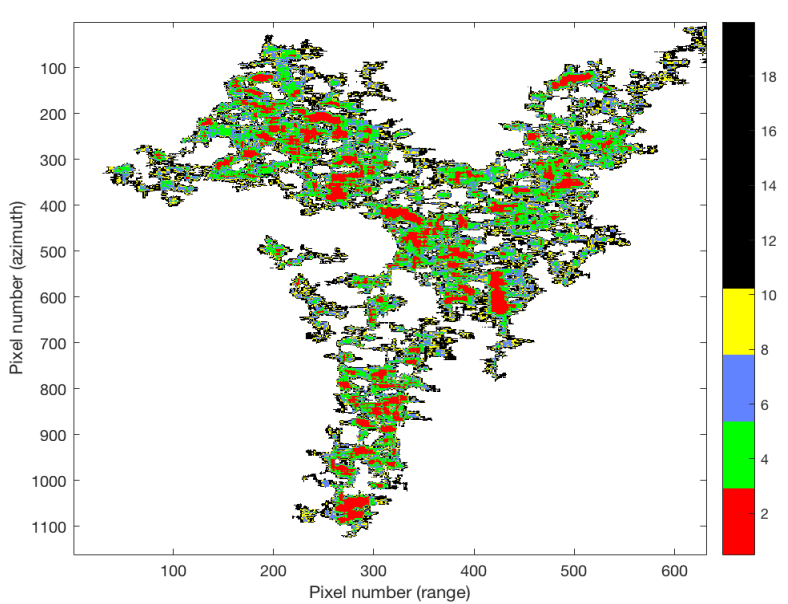

(b) emulsion a

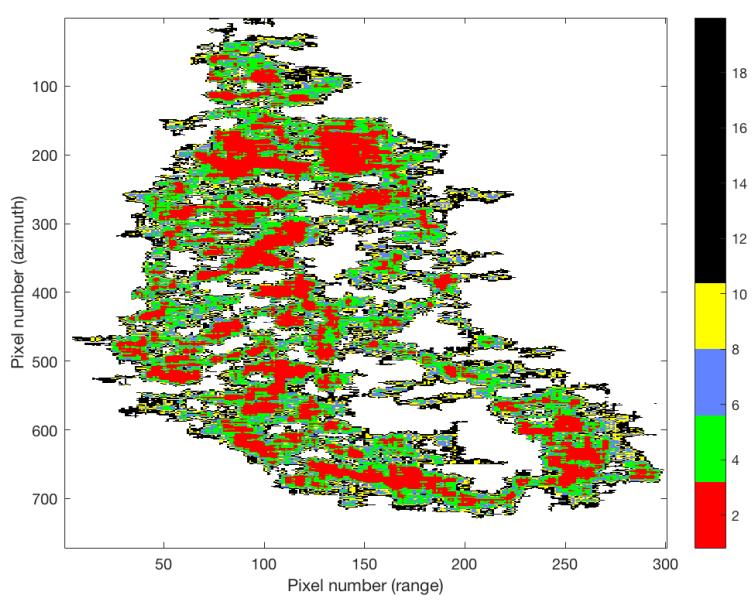

(d) emulsion c

Fig. 7: Inversion results for the four slicks found in $2012 \mathrm{~m}$

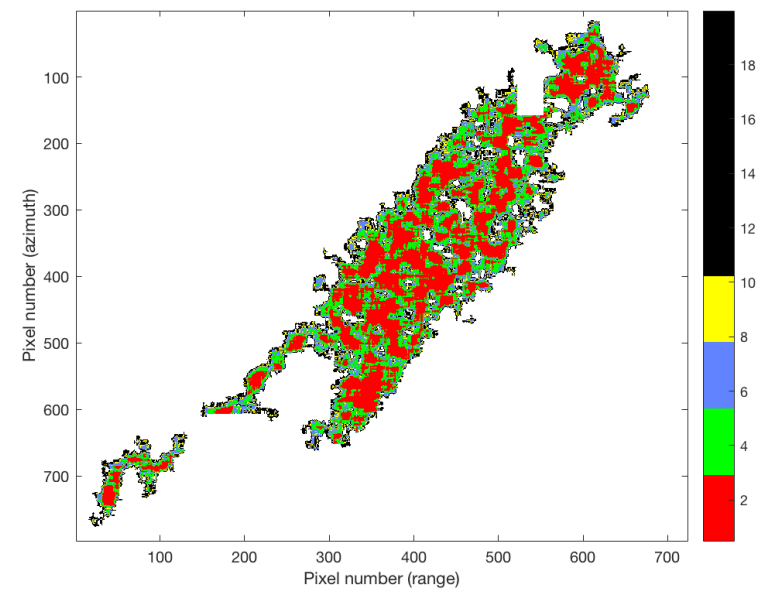

(a) Slick of emulsion results

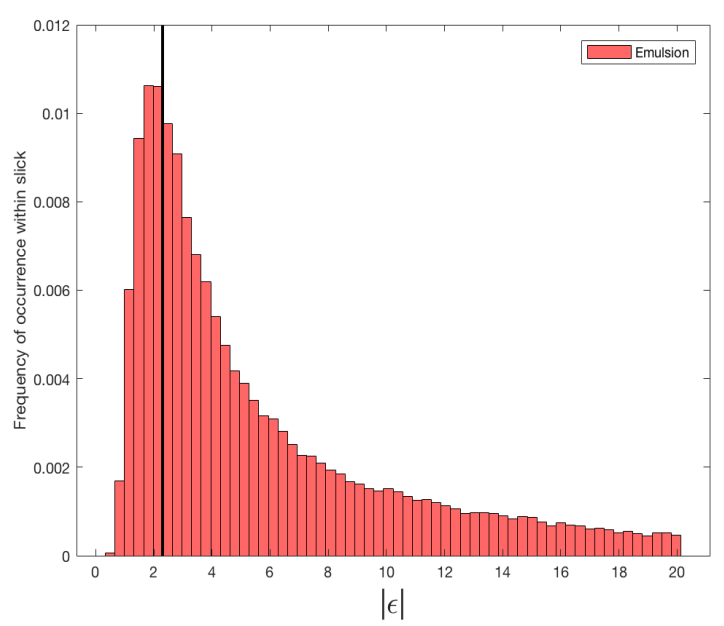

(b) Histogram for slick of emulsion

Fig. 8: (a) inversion results for the slick of emulsion in 2013e. (b) Histogram of $|\varepsilon|$ values for the emulsion slick in (a). The vertical line indicates $|\varepsilon|$ for pure oil and is inserted for reference. 
surface geometry of the underlying ocean. The reduction in backscatter to the SAR, in this case, is purely due to the reduction in surface roughness caused by the sheen.

Fig. 9 (c) shows an area of low wind in the lower left of the image while again the surrounding ocean has a lighter grey appearance in this case. Interestingly, this area appears to have a higher concentration of $|\varepsilon|$ values than the surrounding ocean in the inversion image of Fig. 9 (d). It is unknown why this area is showing a higher concentration of values but one reason may be due to the estimation of $\mathrm{s}$ at the location. As already stated the PTSM is highly sensitive to values of s. Values of s were estimated over the dark patches within the SAR imagery using the surrounding clear ocean areas. If values for s were slightly underestimated, then estimated values of $|\varepsilon|$ for open water would become slightly overestimated. It is worth noting that this is a result of the model's insensitivity at high values of $|\varepsilon|$ i.e. the flatness of the curve. Due to the model's high sensitivity at low values of $|\varepsilon|$, small variations in $s$ are not expected to alter the inversion results significantly over slick infested regions.

These two examples serve to illustrate that low-wind areas, a common oil spill look-alike, and areas of oil sheen, an area with a very thin layer of oil, can be differentiated from either areas of slick in general, or areas of thicker more substantial in quantity oil slick via consideration of the co-polarimetric ratio and inversion results.

\section{CONCLUSIONS}

The application of the PTSM has demonstrated itself to be able to derive reasonable estimates for $|\varepsilon|$ with lower bound values ranging from roughly $1.5-2$ and with the highest values of slick being roughly 20-21. This was observed for all slicks imaged by the sensor.

An interesting observation concerns the distribution of $|\varepsilon|$ values observed over the slick. Slicks, whether being pure crude oil or slicks of emulsion or aged plant oil, tend to have distributions that resemble a Rayleigh distribution. Slicks of plant oil that are sufficiently young, have been shown to have erratic distributions. This may be due to the fact that crude oil and emulsions are believed to result in internal zones of varying thickness whereas biogenic slicks are believed to result in less internal zoning. This may offer one way of determining whether a slick is young biogenic oil or a slick of another variety.

It should be noted that for the 2011 and 2013 campaigns only $0.4 \mathrm{~m}^{3}$ of plant oil was released. In $2011 \mathrm{~m}$, the plant oil was 2 hours old while in 2013e, it was 3.5 hours old. Due to the fact that the plant oil in the inverted 2013e image did not show up, it was concluded that this slick existed as a monomolecular layer at the time of acquisition. As already stated, this is due to the ambiphilic structure of the substance. In the $2011 \mathrm{~m}$ inverted image, the slick of plant oil did not retain the same shape as it did within the polarimetric imagery. This can be seen when comparing the two images of the $2011 \mathrm{~m}$ plant oil contained in Fig.3 (a) and Fig. 4 (c). In section VII.A it was concluded that this was due to the fact that some portions of the slick were thin enough to allow the incoming radiation to be modified solely by the underlying ocean. This could also be an explanation for the "irregular" distribution of the histogram for the plant oil in Fig. 4 (e). When comparing this to the distribution of the histogram for the plant oil contained within 2011e in Fig. 4 (f) and when comparing the spatial extant between the polarimetric imagery in Fig. 3 (b) and the inverted image in Fig.4 (d), we see that the histogram retains a Rayleigh-like distribution and the spatial extant is quite well preserved. It is believed that the reason for this is that at the time of acquisition, the plant oil slick in 2011e is 13 hours old and may have undergone mixing into the water column affecting the dielectric constant of the scattering surface. The implication is that when trying to draw conclusions relating to the plant oil discharges, the age of the slicks is an important factor, more so than the volume of the discharged substance.

An interesting outcome of the application of the PTSM is that areas of low wind were assigned the same values as the open ocean and were not significantly assigned lower $|\varepsilon|$ values than any area of open ocean. Another significant observation is that areas that clearly contain sheen, i.e. a thin film of oil that will cause surface roughness damping but will be transparent to the radar due to their thinness, are also assigned values very similar to that of open ocean. Due to the fact that areas of low wind and areas of sheen were missed by the inversion algorithm, implies that modifications to the returned radar backscatter may solely be due to alterations in the surface geometry of the scattering medium and not its dielectric value.

As this model was applied to data sets containing oil slicks that were subjected to wind speeds between $1.66-5 \mathrm{~m} / \mathrm{s}$, no appreciable effect on retrieval results by the wind speeds were observed. This is an open question however, and can be addressed by applying the model to data sets acquired at higher wind speeds. As for the incidence angle, the effects should not be noticeable as the model accounts for the incidence angle at each pixel, see (3) - (7). This study gives an important contribution to the field in that it shows that it may be possible to infer information of the dielectric properties of slick existing within the ocean environment using $\mathrm{C}$-band radar for low wind conditions. In addition, the results cited in the previous section indicate that by examining the distribution of $|\varepsilon|$ values for plant oil, it may be possible to differentiate between young slicks of natural biogenic oil or slicks of another variety. While the results show values for $|\varepsilon|$ that are around the expected value of 2.3 approximately, some pixels within the slick display underestimated values for $|\varepsilon|$. One possible explanation is due to the corruption of backscatter by internal system noise. Skrunes et. al. [23] showed that over slick filled areas the return to the sensor was very close to the floor, especially for high incidence angles and low wind speeds. The noise estimation procedure employed in this study was designed to remove the noise from the signal that was backscattered to the SAR by making use of the cross-polarization channels. However, accurately determining the amount of noise within a scene is not trivial and may warrant further investigation.

Another possible explanation is the difficulty in estimating the roughness parameter $\mathrm{s}$. This value is estimated from the surrounding ocean area. Given that the distribution of some slicks of oil can be on the scale of kilometers, it is unknown yet if the large-scale roughness outside the slick is representative of the large-scale roughness within the slick. If the value of $\mathrm{s}$ chosen for a pixel within the slick is underestimated, the values for $|\varepsilon|$ obtained will also be underestimated. This could be an explanation for why some pixels within slick have values for 


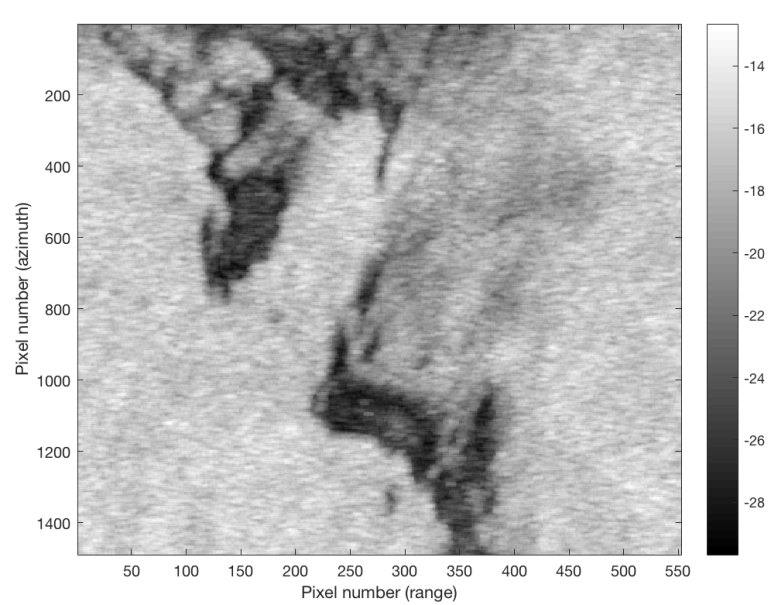

(a) emulsion b as seen in $2012 \mathrm{~m}$

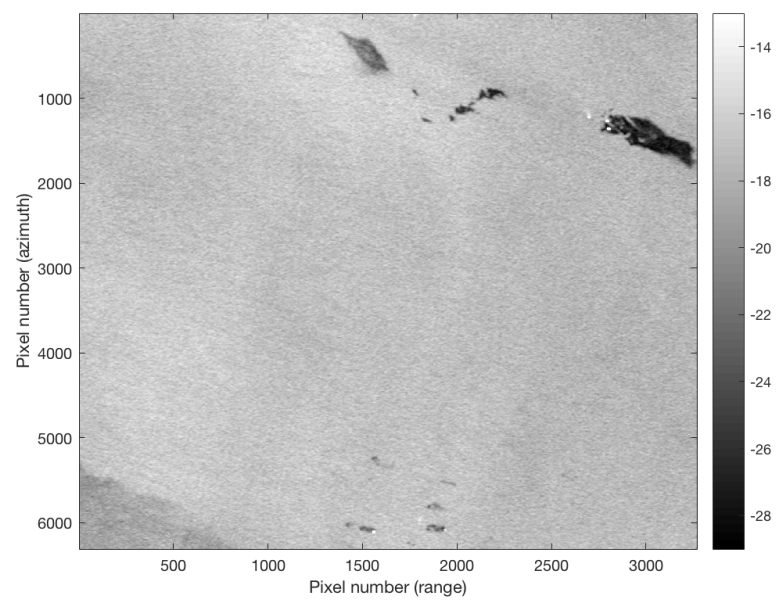

(c) full image of 2011e

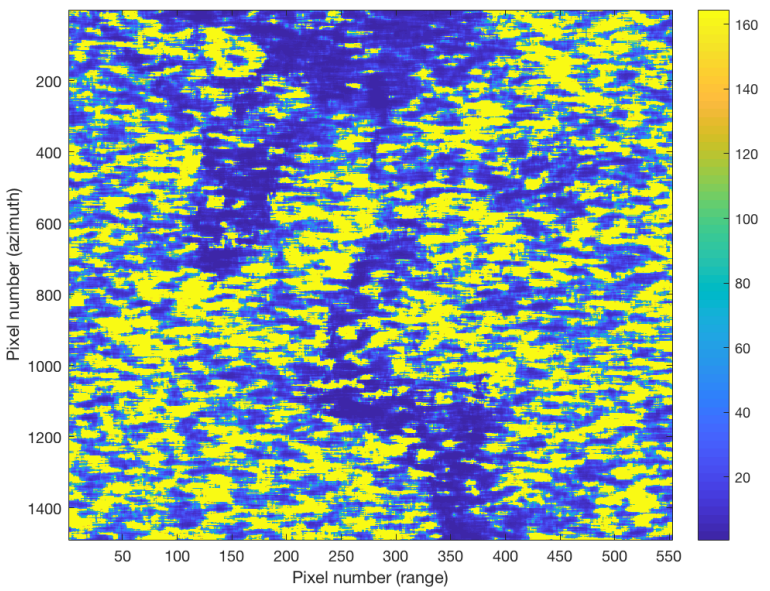

(b) inversion results for emulsion b

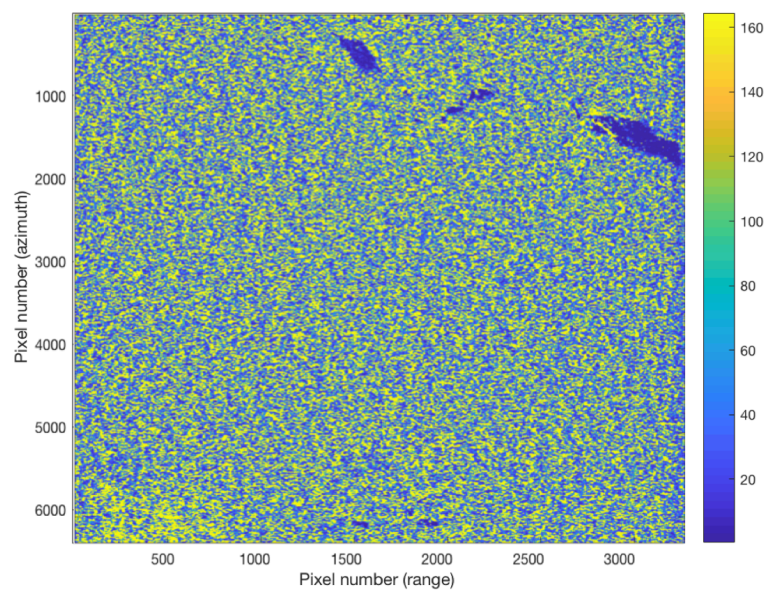

(d) inversion results of 2011 e acquisition

Fig. 9: (a) emulsion b from 2012m scene can be seen as well as oil sheen seen as lighter grey areas. (b) inversion results of (a) showing that areas that contained sheen assume the same inverted values as that of open ocean. (c) full acquisition of the 2011e scene. The lower right corner of the image shows as area of what is believed to be an area of low wind. (d) inversion results of (c) showing that the area that is believed to the low wind assumes that same dielectric values as open water. Note: in (b) and (d) images are not thresholded to 22.

$|\varepsilon|$ less than 2.3. Future work will be conducted to address the uncertainty in obtaining this parameter.

Unfortunately, in-situ data on the conditions of the slicks were not available for the data sets presented in this study, but are being planned to be taken in the NORSE2019 oil-on-water field campaign in the North Sea. Data that is planned to be taken in this campaign includes Quad-polarimetric SAR acquisitions in different frequency bands, i.e. X-, S-, and L-Band, acquired using Deutsches Zentrum für Luft- und Raumfahrt (DLR) F-SAR air bourn instrument which has a lower noise floor than space bourn instruments. These acquisitions will be acquired along with aerial photography and in-situ oil thickness measurements and will be used to confirm the validity of the PTSM approach.

As shown within this study, the combination of the PTSM with C-band SAR images has allowed for the efficient estimation of the modulus of the dielectric constant of marine surface slicks. Sources of uncertainty are shown to be related to the alteration of the original model, which is explained in Appendix A and related to the size of the averaging window used, explained in Appendix B. As in-situ data is not reported it is difficult to say how robust this approach is in practice, however all results presented herein are consistent with surface dwelling marine slicks. If the PTSM approach further demonstrated to provide fast and reliable information on the spatial distribution of oil concentration within slick, it may eventually be used in operational oil spill services to address clean-up efforts 


\section{APPENDIX A}

According to [41], the SPM backscatter cross-section per unit area is defined as

$$
\sigma_{0}^{(1)}(\varepsilon, v)_{p q}=4 \pi k^{4} \cos ^{4} v\left|g_{p q}^{(1)}(\varepsilon, v)\right|^{2} W(2 k \sin v, 0)
$$

Where the $g_{p q}^{(1)}(\varepsilon, v)$ terms are the same as $F_{H}$ and $F_{V}$ in (5) and $v$ the angle of incidence with respect to the normal surface. Note, as we are explicitly indicating the first order nature of the SPM in this section, the notation we employ for the NRCS will diverge slightly from the rest of the paper and will be consistent with [41]. Thus, defining the co-polarization ratio for a single tilted facet using (5) we get the expression

$$
\begin{gathered}
\frac{\sigma_{0}^{(1)}\left(\varepsilon, v_{l}\right)_{V V}}{\sigma_{0}^{(1)}\left(\varepsilon, v_{l}\right)_{H H}}=\left|\frac{g_{V V}^{(1)}\left(\varepsilon, v_{l}\right)}{g_{H H}^{(1)}\left(\varepsilon, v_{l}\right)}\right|^{2}=\left|\frac{F_{V}\left(\varepsilon, v_{l}\right) \cos ^{2} \beta+F_{H}\left(\varepsilon, v_{l}\right) \sin ^{2} \beta}{F_{H}\left(\varepsilon, v_{l}\right) \cos ^{2} \beta+F_{V}\left(\varepsilon, v_{l}\right) \sin ^{2} \beta}\right|^{2}= \\
\left|\frac{\frac{(\varepsilon-1)\left[\sin ^{2} v_{l}-\varepsilon\left(1+\sin ^{2} v_{l}\right)\right]}{\left(\varepsilon \cos v_{l}+\sqrt{\varepsilon-\sin ^{2} v_{l}}\right)^{2}} \cos ^{2} \beta+\frac{\cos _{l}-\sqrt{\varepsilon-\sin ^{2} v_{l}}}{\cos _{l}+\sqrt{\varepsilon-\sin ^{2} v_{l}}} \sin ^{2} \beta}{\mid \frac{\cos _{l}-\sqrt{\varepsilon-\sin ^{2} v_{l}}}{\cos _{l}+\sqrt{\varepsilon-\sin ^{2} v_{l}}} \cos ^{2} \beta+\frac{(\varepsilon-1)\left[\sin ^{2} v_{l}-\varepsilon\left(1+\sin ^{2} v_{l}\right)\right]}{\left(\varepsilon \cos v_{l}+v_{l}\right)^{2}} \sin ^{2} \beta}\right|^{2}
\end{gathered}
$$

As $\varepsilon$ is a complex quantity, the inversion of (12) for $\varepsilon$ is computationally complex. Throughout this study the co-pol ratio is assumed to have the more tractable form

$$
\begin{aligned}
& \frac{\sigma_{0}^{(1)}\left(|\varepsilon|, v_{l}\right)_{V V}}{\sigma_{0}^{(1)}\left(|\varepsilon|, v_{l}\right)_{H H}} \\
& =\left(\frac{\frac{(|\varepsilon|-1)\left[\sin ^{2} v_{l}-|\varepsilon|\left(1+\sin ^{2} v_{l}\right)\right]}{\left(|\varepsilon| \cos v_{l}+\sqrt{|\varepsilon|-\sin ^{2} v_{l}}\right)^{2}} \cos ^{2} \beta+\frac{\cos v_{l}-\sqrt{|\varepsilon|-\sin ^{2} v_{l}}}{\cos v_{l}+\sqrt{|\varepsilon|-\sin ^{2} v_{l}}} \sin ^{2} \beta}{\frac{\cos v_{l}-\sqrt{|\varepsilon|-\sin ^{2} v_{l}}}{\cos v_{l}+\sqrt{|\varepsilon|-\sin ^{2} v_{l}}} \cos ^{2} \beta+\frac{(|\varepsilon|-1)\left[\sin ^{2} v_{l}-|\varepsilon|\left(1+\sin ^{2} v_{l}\right)\right]}{\left(|\varepsilon| \cos v_{l}+v_{l}\right)^{2}} \sin ^{2} \beta}\right)^{2}
\end{aligned}
$$

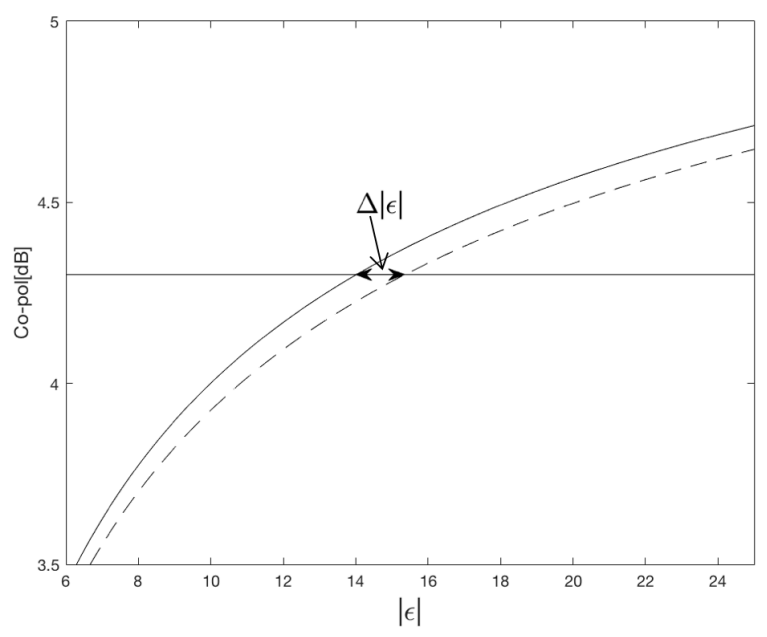

Fig. 10: Image showing the difference in $|\varepsilon|$ values between (12), solid line and (13), dashed line.

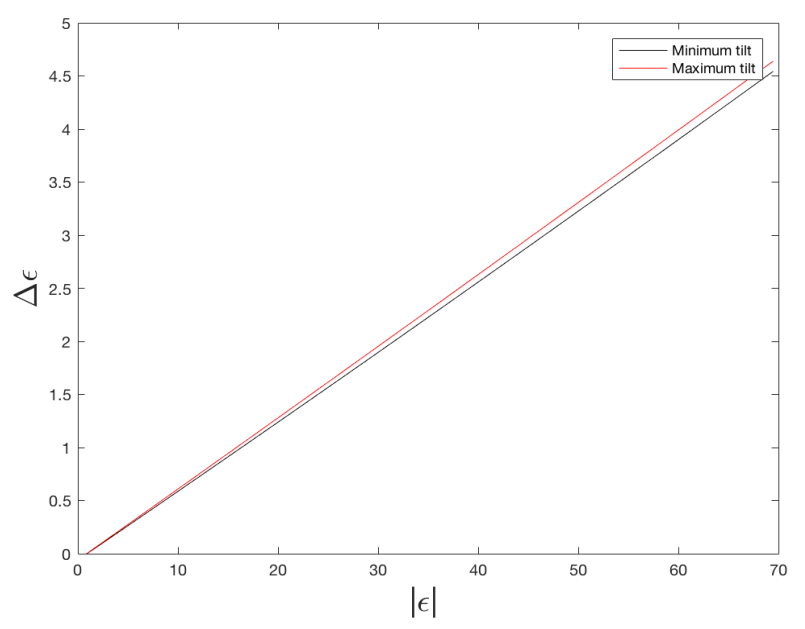

(a) $2011 \mathrm{e}$

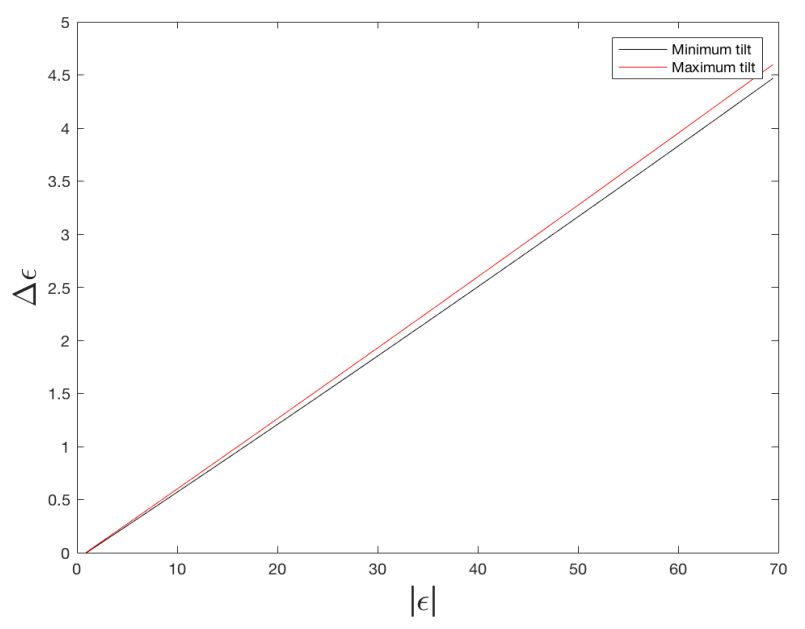

(b) $2013 \mathrm{e}$

Fig. 11: Difference curves for (a) 2011e and (b) 2013e. Both curves are nearly identical. Low values for $|\varepsilon|$ result in small inversion

In this Appendix, we explicitly demonstrate the error that is incurred by implementing (13) instead of (12).

In order to determine the effect of using (13) over (12) in the PTSM we consider the co-pol ratio for scattering from a single tilted facet for the cases where a and b, the local azimuth and range slopes respectively, are considered at their extrema. For this we consider the following 2 cases where [a,b] take the values of $[0,0]$ and $[0.2,0.2]$ respectively. For the case where $[a, b]$ take the values of $[0,0]$ the scattering from the facet is described solely by the small perturbation model. When $[\mathrm{a}, \mathrm{b}]$ take the values of $[0.2,0.2]$ the facet is at its maximum possible angle of tilt before wave breaking occurs [42].

In Fig. 10 the solid black line corresponds to equation (12) while the dotted line corresponds to equation (13). When performing an inversion for a $|\varepsilon|$ value a value that corresponds to (12) should be received. Instead a value that corresponds to (13) is retrieved. The error that is incurred, $\Delta|\varepsilon|$, is a function of $|\varepsilon|$ with small values occurring for small $|\varepsilon|$ values and larger 
values occurring for larger values of $|\varepsilon|$.

Fig. 11 (a) and (b) shows the curves that correspond to $\Delta|\varepsilon|$ for two slicks, one from 2011e and one from 2013e. These two slicks were chosen as the scenes in which they come from have incidence angles of $34^{\circ}$ and $28^{\circ}$ respectively, and were chosen to highlight the effect of using (13) and (12) using the broadest range of incidence angles available from the data. Note, the $2011 \mathrm{~m}$ scene, which had an incidence angle of around $46^{\circ}$ was excluded from this part of the analysis as a noise analysis conducted by [23] showed that this particular data set was particularly noisy. The red curves correspond to $\Delta|\varepsilon|$ when the facet has a maximum possible value of tilt and the black curve corresponds to $\Delta|\varepsilon|$ for when the facet has a minimum value of tilt. As can be seen the maximum and minimum curves are similar as well as the fact that $\Delta|\varepsilon|$ has small values for low $|\varepsilon|$ areas, i.e. slick filled areas.

\section{APPENDIX B}

In order to test the effects of speckle on the retrieval results a small 100x100 pixel section of 2013e was chosen for analysis. This individual section will be used to demonstrate that the model is robust against the level of speckle present in the SAR image in terms of retrieving s. The 2013e acquisition was chosen as it has the lowest angle of incidence and the highest wind speed amongst all the scenes considered. This 100x100 pixel sized section can be seen in Fig.12 (a) and is delineated by a red square.

Fig. 12 (b) shows the co-polarimetric scatter, shown in red, from the 100x100 pixel averaged under different window sizes. The size of the averaging windows are displayed on the $\mathrm{x}$-axis of the graph shown in Fig. 12 (b). The blue $\mathrm{X}$ delineates the average of the co-polarimetric scatter. As can be seen the averaging only serves to reduce the variance of the distribution of the scatter while preserving the expectation value.

Following the procedure outlined in section IV.A, the value for s that was found for each instance to be the same and had a value of 0.213 .

Although only a small region was chosen for this analysis it does serve to illustrate that speckle will have little effect on the expectation of the retrieval results but only the variance.

In order to examine what the effect of the decreasing variance with increasing averaging window size is on the retrieval results, the following curve was plotted which corresponds to the value for $\mathrm{s}$ and incidence angle for the square region in Fig. 12 (a).

Fig. 13 (a) shows a specific range of co-polarimetric values and their corresponding $|\varepsilon|$ values. This is denoted by the solid black line. The dashed line indicates the center of the copolarimetric distribution and is shown along with its corresponding $|\varepsilon|$ value.

Fig.13 (b) shows a graph of the central $|\varepsilon|$ values on the $\mathrm{x}$ axis along the range of found $|\varepsilon|$ values, denoted by $\Delta|\varepsilon|$. This was plotted for different ranges of co-polarimetric values i.e. $0.2,0.4,0.6$ and $0.8 \mathrm{~dB}$. As can be seen, for small values of variance, the uncertainty in $|\varepsilon|$ rises more slowly than higher values of variance.

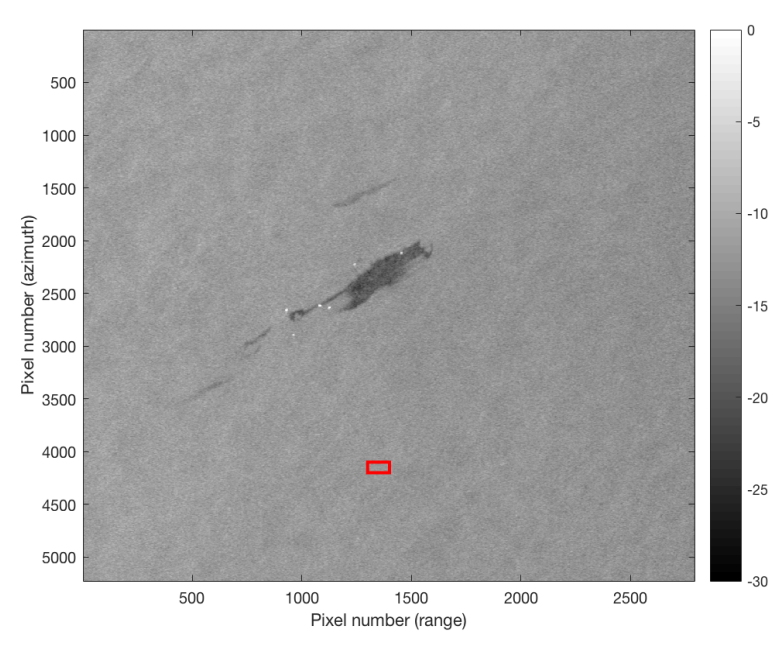

(a)

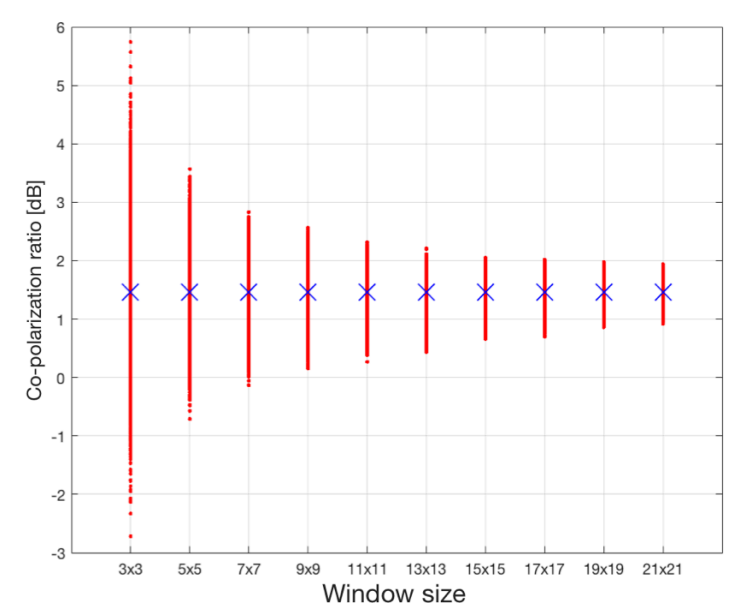

(b)

Fig. 12: (a) 2013e scene showing 100x100 pixel region that was chosen for analysis outlined in red. (b) Copolarization scatter shown in red with mean values shown in blue. Values for $s$ were the same for every size of averaging filter used.

\section{REFERENCES}

[1] A.Carpenter, "European maritime safety agency CleanSeaNet activities in the North Sea. Oil pollution in the North Sea" in The Handbook of Environmental Chemistry, 41. Springer International Publishing Cham., pp.33-48.

[2] ITOPF, "Aerial observations of marine oil spills," Inter. Tanker Owners Poll. Fed., London, UK, Tech. Info. Paper, no. 1,2011

[3] M. Fingas, "The challenges of remotely measuring oil slick thickness," Remote Sensing, vol.10, no. 2, p.319,2018.

[4] M. Fingas, "How to measure oil thickness (or not)," AMOP, Environment Canada, Ottawa, Ontario, pp. 617-652, 2012.

[5] Bonn Agreement Secretariat, "Bonn Agreement Aerial Operations Handbook", London, UK, Tech. Info. Paper, $2016 . \quad$ Available: https://www.bonnagreement.org/site/assets/files/1081/aeria a_operations_handbook.pdf, Accessed on: Dec. 18, 2019. 


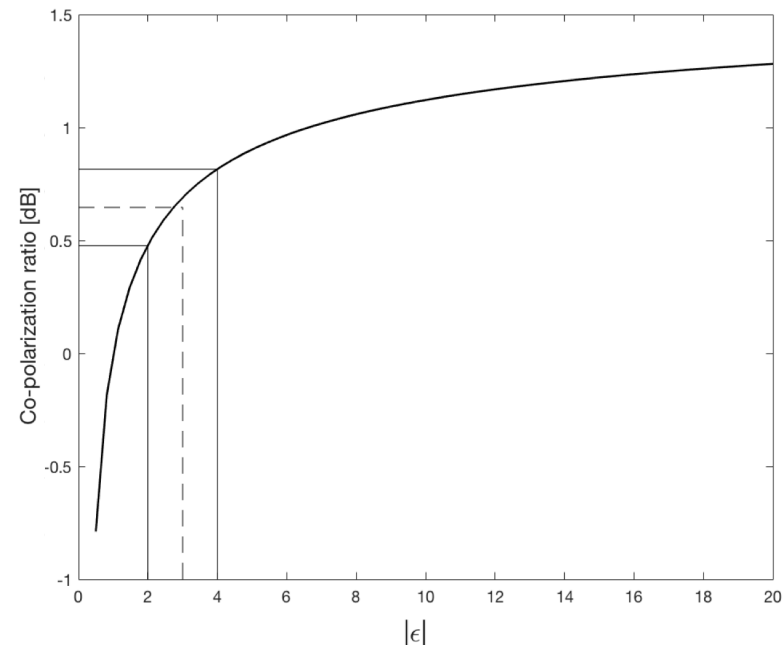

(a)

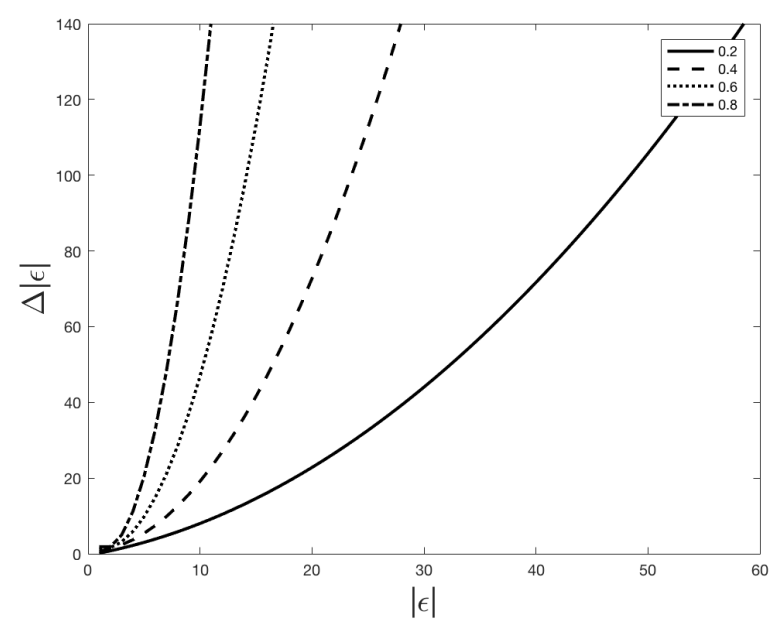

(b)

Fig. 13: (a) PTSM curve colısponding to the red region in Fig. 12 (a). The portion of the co-polarization ratio denoted by the solid lines indicate the variance, the dashed lines indicate the central $|\varepsilon|$ value that is obtained. (b) Various curves showing the effect of variance on retrieval results. The central value denoted by the dashed line in (a) is plotted along the $\mathrm{x}$ axis while the span of $|\varepsilon|$ denoted by the solid black lines in (a) is platted along the y axis.

[6] W. Alpers, B. Holt, K. Zeng, "Oil spill detection by imaging radars: Challenges and pitfalls", Remote Sens. Environ., vol. 201, pp. 133-147, Nov. 2017.

[7] C. Elachi and J. van Zyl, "Ocean surface sensing," in Introduction to the physics and techniques of remote sensing, 2nd ed., NJ, USA: John Wiley and Sons, 2006, pp. 379.

[8] S. Skrunes, C. Brekke, M.M. Espeseth, "Assessment of the RISAT-1 FRS-2 mode for oil spill observation" in IEEE IGARSS, Fort Worth, TX, USA, 2017, pp.1024-1027.

[9] B. Minchew, C. E. Jones, B. Holt, "Polarimetric analysis of backscatter from the Deepwater Horizon oil spill using Lband synthetic aperture radar", IEEE Trans. Geosci. Remote Sens., vol. 50, no. 10, pp. 3812-3830, Oct. 2012.
[10] J. Coleman, Ed., Oil in the Sea III: Inputs, Fates and Effects. The National Academic Press, 2003.

[11] B. Minchew, "Determining the mixing of oil and sea water using polarimetric synthetic aperture radar," Geophys. Res. Lett., vol. 39, 2012.

[12] S. Angelliaume, O. Boisot, C.A. Guerin, "Dual-Polarized L-Band SAR Imagery for Temporal Monitoring of Marine Oil Slick Concentration," Remote Sens., vol. 10, no. 7, Jul. 2018.

[13] M. J. Collins, M. Denbina, B. Minchew, C. E. Jones, B. Holt, "On the use of simulated airborne compact polarimetric SAR for characterizing oil-water mixing of the Deepwater horizon oil spill", IEEE J. Sel. Topics Appl. Earth Observ. Remote Sens., vol. 8, no. 3, pp. 1062-1077, Mar. 2015.

[14] H. Li, W. Perrie, J. Wu, "Retrieval of Oil-Water Mixture Ratio at Ocean Surface Using Compact Polarimetry Synthetic Aperture Radar," Remote Sens., vol. 11, no. 7, Apr. 2019.

[15] I. Hajnsek, E. Pottier, S. R. Cloude, "Inversion of surface parameters from polarimetric SAR", IEEE Trans. Geosci. Remote Sens., vol. 41, no. 4, pp. 727-744, Apr. 2003.

[16] A. Iodice, A. Natale, D. Riccio, "Retrieval of soil surface parameters via a polarimetric two-scale model", IEEE Trans. Geosci. Remote Sens., vol. 49, no. 7, pp. 2531-2547, Jul. 2011.

[17] H. Huhnerfuss, "Basic physicochemical principles of monomolecular sea slicks and crude oil spills," in Marine Surface Films, M. Gade, H. Huhnerfuss and G.M. Korenowski, Eds. Springer-Verlag Berlin Heidelberg, 2006, pp. 21-35.

[18] G. Yasin, M.I. Bhanger, T.M. Ansari, S.M.S.R. Naqvi, M.Ashraf, K Ahmad, F.N. Talpur, "Quality and chemistry of crude oil", J. of Petro. Tech. and Alter. Fuels, vol 4, no 3, pp. 53-63, March 2013.

[19] ITOPF, "Fate of marine oil spills," Inter. Tanker Owners Poll. Fed., London, UK, Tech. Info. Paper, no.2, 2011

[20] C.E. Jones, M.M. Espeseth, B. Holt, C. Brekke, S. Skrunes, "Characterization and discrimination of evolving mineral and plant oil slicks based on L-band synthetic aperture radar (SAR)," in Proc. of SPIE, Edinburgh, Scotland, UK, 2016

[21] T. Friisø, Y. Schildberg, O. Rambeau, T. Tjomsland, H. Førdedal, J. Sjøblom, "Complex permittivity of crude oils and solutions of heavy crude oil fractions", J. Dispersion Sci. Technol., vol. 19, no. 1, pp. 93-126, 1998.

[22] S. Skrunes, C. Brekke, T. Eltoft, V. Kudryavtsev, "Comparing near-coincident $\mathrm{C}$ - and X-band SAR acquisitions of marine oil spills", IEEE Trans. Geosci. Remote Sens., vol. 53, no. 4, pp. 1958-1975, Apr. 2015.

[23] S. Skrunes, C. Brekke, T. Eltoft, "Characterization of marine surface slicks by Radarsat-2 multipolarization features", IEEE Trans. Geosci. Remote Sens., vol. 52, no. 9, pp. 5302-5319, Sep. 2014.

[24] J. P. Hollinger and R. A. Mennella, "Oil spills: measurements of their distributions and volumes by multifrequency microwave radiometry," Science, vol. 181, no. 4094, pp. 54-56, Jul. 1973.

[25] D. V. Ivonin, S. Skrunes, C. Brekke, A. Y. Ivanov, "Interpreting sea surface slicks on the basis of the normalized radar cross-section model using RADARSAT-2 
co-polarization dual-channel SAR images", Geophys. Res. Lett., vol. 43, no. 6, pp. 2748-2757, 2016.

[26] A. Montuori, F. Nunziata, M. Migliaccio, P. Sobieski, "Xband two-scale sea surface scattering model to predict the contrast due to an oil slick", IEEE J. Sel. Topics Appl. Earth Observ. Remote Sens., vol. 9, no. 11, pp. 4970-4978, Nov. 2016.

[27] N. Pinel, C. Bourlier, I. Sergievskaya, "Two-dimensional radar backscattering modeling of oil slicks at sea based on the model of local balance: Validation of two asymptotic techniques for thick films", IEEE Trans. Geosci. Remote Sens., vol. 52, no. 5, pp. 2326-2338, May 2014.

[28] N. Pinel, N. Déchamps, C. Bourlier, "Modeling of the bistatic electromagnetic scattering from sea surfaces covered in oil for microwave applications", IEEE Trans. Geosci. Remote Sens., vol. 46, no. 2, pp. 385-392, Feb. 2008.

[29] B.-L. Li, "Fractal dimensions," in Encyclopedia of Environmetrics, vol. 2, A.H. El-Shaarawi, W.W. Piegorsch, Ed. West Sussex, England, UK, 2002, pp. 821-825.

[30] M. Stiassnie, Y. Agnon, L. Shemer, "Fractal dimensions of random water surfaces," Physica D, vol. 47, no.3, pp. 341352, Jan 1991.

[31] A. H. Sihvola, "Self-consistency aspects of dielectric mixing theories", IEEE Trans. Geosci. Remote Sens., vol. 27, no. 4, pp. 403-415, Jul. 1989.

[32] I. Hajnsek, K. P. Papathanassiou, S. R. Cloude, "Removal of additive noise in polarimetric eigenvalue processing", Proc. IGARSS, pp. 2778-2780, 2001.

[33] T. Meissner, F. J. Wentz, "The complex dielectric constant of pure and sea water from microwave satellite observations", IEEE Trans. Geosci. Remote Sens., vol. 42, no. 9, pp. 1836-1849, Sep. 2004.

[34] S. Skrunes, C. Brekke, A. P. Doulgeris, "Characterization of low-backscatter ocean features in dual-copolarization SAR using log-cumulants", IEEE Geosci. Remote Sens. Lett., vol. 12, no. 4, pp. 836-840, Apr. 2015.

[35] MDA, "Radarsat-2 product description", Maxar Tech. Ltd., Richmond, B.C., Canada, Tech. Rep., RN-SP-521238, Sept. 2018.

[36] A. Melbye, "NOFO oljevernøvelse, olje på vann 2013", NOFO, Norway, Rep. F11999, June 10-14 2013.

[37] O. Boisot, S. Angelliaume, C.-A,Guerin, "Marine oil slicks quantification from L-band dual-polarization SAR imagery", IEEE Trans. Geosci. Remote Sens., vol. 50, no. 10, pp. 3812-3830, Oct. 2012.

[38] J. C. McWilliams, and P . P . Sullivan, "Vertical mixing by Langmuir circulations," Spill Science \& Technology Bulletin, vol. 6, no. 3-4, pp. 225-237, 2000.

[39] W. J. Lehr, D. Simecek-Beatty, "The relation of Langmuir circulation processes to the standard oil spill spreading dispersion and transport algorithms", Spill Sci. Technol. Bulletin, vol. 6, no. 3, pp. 247-253, 2000.

[40] H. Rye, "Probable effects of Langmuir circulation observed on oil slicks in the field", Spill Sci. Technol. Bulletin, vol. 6, no. 3, pp. 263-271, 2000.

[41] G. R. Valenzuela, "Theories for the interaction of electromagnetic waves and oceanic waves. A review", Bound. Layer Meteorol., vol. 13, no. 14, pp. 61-85, Jan. 1978.
[42] W.Munk, "An inconvenient sea truth: Spread, steepness, skewness of surface slopes, "Ann. Rev. Marine Sci., vol. 1, pp. 377-415, Jan. 2009.

\section{ACKNOWLEDGMENT}

The authors wish to thank Veronique Miegebielle from Total E\&P for her contributions to the preparation on this manuscript.

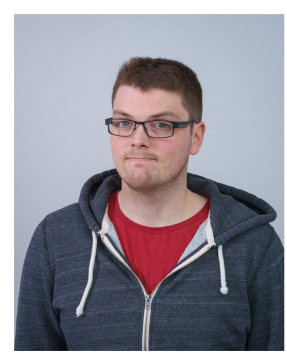

Cornelius Quigley received his Bachelor degree in Physics in June 2013 from the Department of Physics at the National University of Ireland, Cork. He received his Master's degree from the Department of Physics and Technology at the University of Troms $\emptyset$ - The Arctic University of Norway in June 2017. He started as a PhD student at the same department in September 2017, with the Center for Integrated Remote Sensing and Forecasting for Arctic Operations (CIRFA). His current research interests include remote sensing of ocean areas, specifically by polarimetric SAR and with a focus on marine oil pollution.

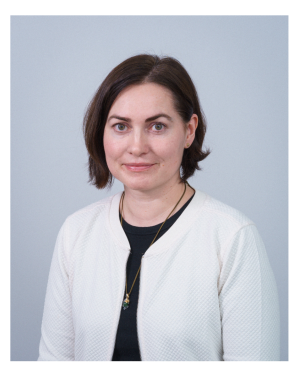

Camilla Brekke (M'12) is Vice-Dean Research at the Faculty of Science and Technology (since 2018) and Deputy Centre Leader (since 2019) at Centre for Integrated Remote Sensing and Forecasting for Arctic Operations (CIRFA) at Department of Physics and Technology, UiT The Arctic University of Norway, Troms $\varnothing$, Norway. She received the Cand. Mag., Cand. Scient., and $\mathrm{Ph} . \mathrm{D}$. degrees from the University of Oslo, Oslo, Norway, in 1998, 2001, and 2008, respectively. She was an exchange student to National University of Singapore in 1998 (spring). In 2001, she was a System Developer with Ericsson, Asker, Norway. From 2001 to 2002, she was a Young Graduate Trainee with the European Space Agency, Noordwijk, The Netherlands. From 2002 to 2009, she was a Scientist with the Norwegian Defense Research Establishment, Kjeller, Norway. In 2009, she joined the Department of Physics and Technology, UiT The Arctic University of Norway as an Associate Professor. Brekke is a full Professor since 2016. From 2012 to 2013 (4 months) and in 2018 (4 months), she was a visiting scholar at the Jet Propulsion Laboratory, California Institute of Technology, Pasadena, CA, USA. Her research interests include synthetic aperture radar and ocean colour remote sensing for arctic and marine applications.

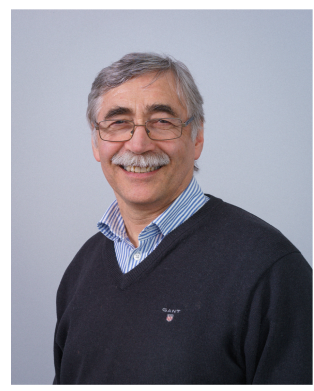

Torbjørn Eltoft (M'92) received the degrees of Cand. Real. (M.S.) and Dr. Scient. (Ph.D.) from University of Troms $\emptyset$ - The Arctic University of Norway, in 1981 and 1984, respectively. In 1988 he joined the Faculty of Science, University of Tromsø - The Arctic University of Norway, and is presently Professor in electrical engineering at the Department of Physics and Technology, where he also is head of the Earth Observation Laboratory and of the BARESS Remote Sensing School. He also holds a position as Adjunct Professor at Norut, Troms $\emptyset$. His current research interests include multidimensional signal and image analysis with application in remote sensing, statistical models, neural networks, and machine learning. Dr. Eltoft has been associate editor of the journal Pattern Recognition for five years. He was awarded the year 2000 Outstanding Paper Award in Neural Networks by IEEE Neural Networks Council, and Honorable Mention for the 2003 Pattern Recognition Journal Best Paper Award. 